San Jose State University

SJSU ScholarWorks

Master's Theses

Master's Theses and Graduate Research

1991

\title{
Quantitative and qualitative comparison between acceleration control and pulse control in spacecraft docking
}

Adam Randall Brody

San Jose State University

Follow this and additional works at: https://scholarworks.sjsu.edu/etd_theses

\section{Recommended Citation}

Brody, Adam Randall, "Quantitative and qualitative comparison between acceleration control and pulse control in spacecraft docking" (1991). Master's Theses. 99.

DOI: https://doi.org/10.31979/etd.5ezn-gdnu

https://scholarworks.sjsu.edu/etd_theses/99

This Thesis is brought to you for free and open access by the Master's Theses and Graduate Research at SJSU ScholarWorks. It has been accepted for inclusion in Master's Theses by an authorized administrator of SJSU ScholarWorks. For more information, please contact scholarworks@sjsu.edu. 


\section{INFORMATION TO USERS}

This manuscript has been reproduced from the microfilm master. UMI films the text directly from the original or copy submitted. Thus, some thesis and dissertation copies are in typewriter face, while others may be from any type of computer printer.

The quality of this reproduction is dependent upon the quality of the copy submitted. Broken or indistinct print, colored or poor quality illustrations and photographs, print bleedthrough, substandard margins, and improper alignment can adversely affect reproduction.

In the unlikely event that the author did not send UMI a complete manuscript and there are missing pages, these will be noted. Also, if unauthorized copyright material had to be removed, a note will indicate the deletion.

Oversize materials (e.g., maps, drawings, charts) are reproduced by sectioning the original, beginning at the upper left-hand corner and continuing from left to right in equal sections with small overlaps. Each original is also photographed in one exposure and is included in reduced form at the back of the book.

Photographs included in the original manuscript have been reproduced xerographically in this copy. Higher quality 6" $\times$ 9" black and white photographic prints are available for any photographs or illustrations appearing in this copy for an additional charge. Contact UMI directly to order.

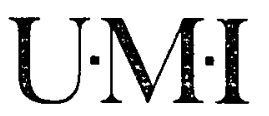

University Microfilms International

A Bell \& Howell Information Company 

Order Number 1844245

Quantitative and qualitative comparison between acceleration control and pulse control in spacecraft docking

Brody, Adam Randall, M.A.

San Jose State University, 1991

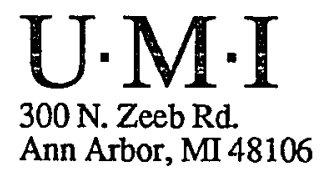





\title{
QUANTITATIVE AND QUALTTATTVE COMPARISON BETWEEN ACCELERATION CONTROL AND PULSE CONTROL IN SPACECRAFT DOCKING
}

\author{
A Thesis \\ Presented to \\ the Faculty of the Department of Psychology \\ San Jose State University \\ In Partial Fulfillment \\ of the Requirements for the Degree \\ Míaster of Árts
}

by

Adam Randall Brody

May, 1991 


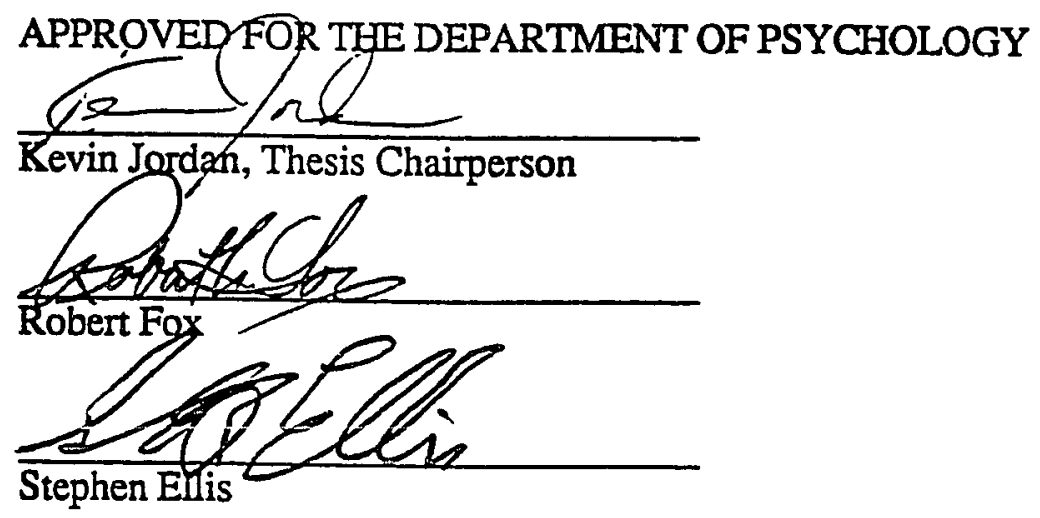

APPROVED FOR THE UNIVERSITY

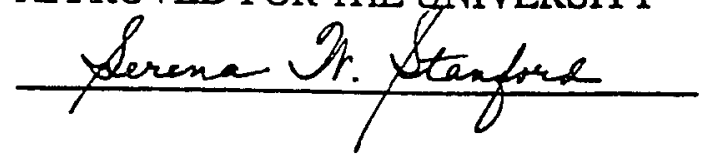




\title{
ABSTRACT \\ QUANTITATIVE AND QUALITATIVE COMPARISON BETWEEN ACCELERATION CONTROL AND PULSE CONTROL IN SPACECRAFT DOCKING \\ by Adam Randall Brody
}

\begin{abstract}
Nine commercial airline pilots served as test subjects in a study designed to compare acceleration control with pulse control in simulated spacecraft docking maneuvers. Simulated remote dockings of an orbital maneuvering vehicle (OMV) to a space station were initiated from 50,100, and 150 meters along the station's -V-bar (minus velocity vector). Mission duration was lower with pulse mode while velocity increment (fuel consumption) was lower with acceleration mode. Subjects used more fuel to travel faster with pulse mode than with acceleration mode. Mission duration, velocity increment (and its components: $\mathrm{X}$ velocity increment, $\mathrm{Y}$ velocity increment, and $\mathrm{Z}$ velocity increment) all increased with range. These higher average velocities were paid for with increased fuel consumption. Asymmetrical transfer was found; the mode transitions could not be predicted solely from the mission duration main effect. More testing is advised to understand the manual control aspects of spaceflight maneuvers better.
\end{abstract}




\section{DEDICATION}

To the men in the astronaut program, oh, that I were one of them.

Buzz Aldrin, Men From Earth, p. 71, 1989

Docking was another major hurdle that had to be overcome if we were to make it to the Moon. Normally, it went well but I always breathed easier when it was behind us.

Christopher C. Kraft, Jr.

This has been far more than three men on a mission to the Moon; more, still, than the efforts of a government and industry team; more, even, than the efforts of one nation. We feel that this stands as a symbol of the insatiable curiosity of all mankind to explore the unknown. Today I feel we're really fully capable of accepting expanded roles in the exploration of space.

Edwin E. Aldrin, Jr.

And both of our flights, as did earlier and later missions, pointed up the advantage of manned space exploration. We all were able to make minor corrections or major changes at times when they were needed, sometimes for better efficiency, and sometimes to save the mission.

Alan B. Shepard, Jr., 1975

That lonesome, marbled bit of blue with ancient seas and continental rafts is our planet, our home as men travel the solar system. The challenge for all of us is to guard and protect that home, together, as people of Earth.

Harrison H. Schmitt

Space is, almost by its very character, a presidential issue.

Dr. John Logsdon, 1988

We choose to go to the moon in this decade and do the other things, not because they are easy, but because they are hard.

President John F. Kennedy, 1961

We will not abandon our dream. We will never evacuate the frontiers of space to any other nation.

President Lyndon B. Johnson, 1967

During Apollo missions, we were pilgrims in space, in search of knowledge. Now we will become shepherds, tending our technological flocks.

President Jimmy Carter, 1978

To seize this opportunity ... I'm proposing a long-range, continuing commitment: ... for the 1990's, Space Station Freedom ... for the new century--back to the moon. Back to the future. And this time back to stay ... and then a journey into tomorrow ... a mission to Mars.

President George Bush, 1989 


\section{ACKNOWLEDGMENTS}

I would like to thank the members of my thesis committee for their assistance. Their suggestions concerning experimental protocol, content, theory, and APA formatting constituted important contributions to this paper. Gratitude is also shown to BB for reloading his industrial strength red ink pen one more time.

Financial support for this work was provided by both NASA Ames Research Center and Sterling Software. Drs. Bruce Webbon, Stephen Ellis, and Michael Shafto paid for my time while I designed the experiment, wrote the computer code, collected the data, analyzed the results, and wrote the thesis. Sterling Software, my employer, paid for my tuition and supplies.

Astronomy compels the soul to look upward, and leads us from this world to another. Plato, The Republic, 342 B.C.

The earth is the cradle of humanity, but mankind will not stay in the cradle forever. Konstantin I. Tsiolkovsky, Outside the Earth, 1903

We shall not cease from exploration and the end of all our exploring will be to arrive where we started and know the place for the first time.

T.S. Eliot, Four Quartets, 1943

One nice thing about Apollo was that no one ever told us we were running the price up too high.

Michael Collins, Carrying the Fire, 1967

Don't let the past remind us of what we are not now.

Stephen Stills, Suite: Judy Blue Eyes, 1969

In the long run, scientific knowledge is the most valuable, and often most culturally enriching, of all resources.

Arthur C. Clarke, 1980

To live in the perpetual free fall of orbital flight is to be confronted with example after example of simple classical physics in wonderful and extraordinary detail.

Joseph P. Allen, Physics at the Edge of the Earth, 1988

Nevertheless, the evidence was conclusive. The astronauts could have done it on their own without any ground assistance whatsoever!

Richard H. Battin, Some Funny Things Happened on the Way to the Moon, 1989 


\section{TABLE OF CONTENTS}

SECTION

PAGE

DEDICATION iv

ACKNOWLEDGMENTS.......................................................

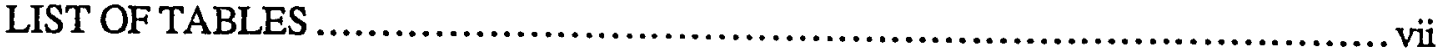

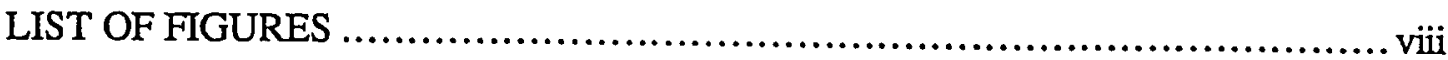

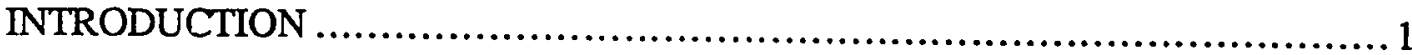

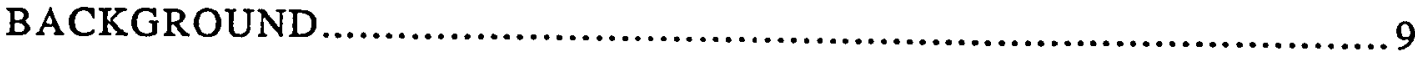

American Docking Experience............................................ 9

Soviet Docking Experience.................................................... 10

Docking Failures. ............................................... 20

Docking Recoveries..............................................22

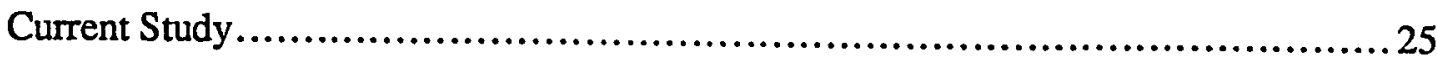

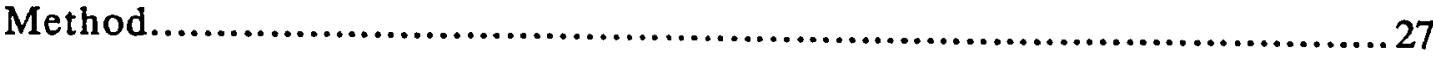

Subjects............................................................ 27

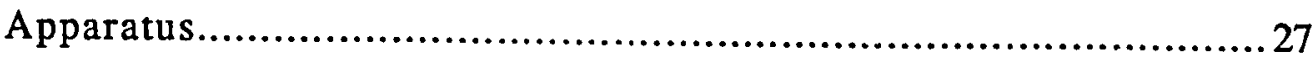

Procedure............................................................. 28

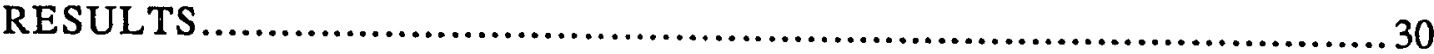

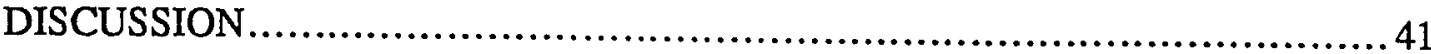

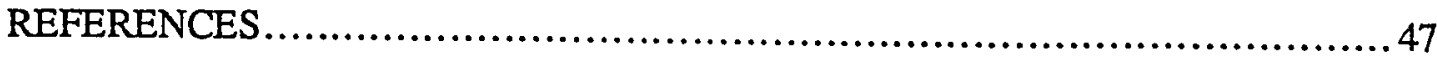

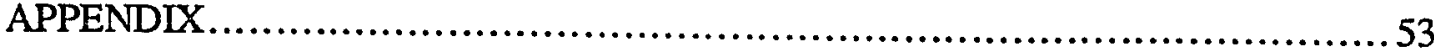




\section{LIST OF TABLES}

TABLE PAGE

1. Significant effects from ANOVA.................................................. 31 


\section{LIST OF FIGURES}

FIGURE PAGE

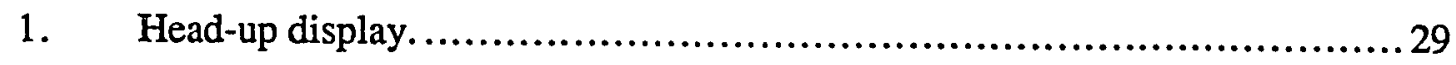

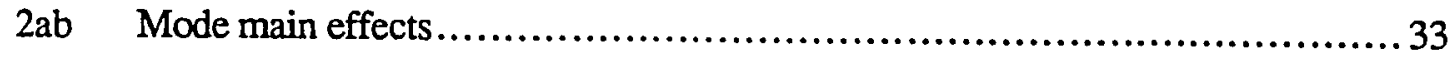

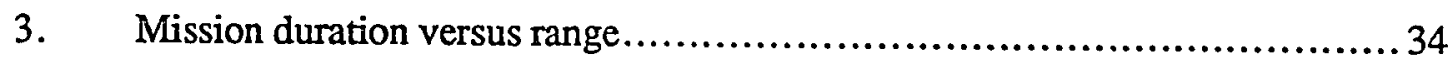

4. Velocity increment components versus range....................................36

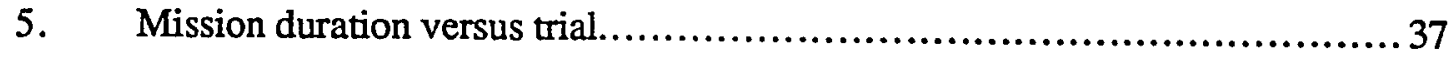

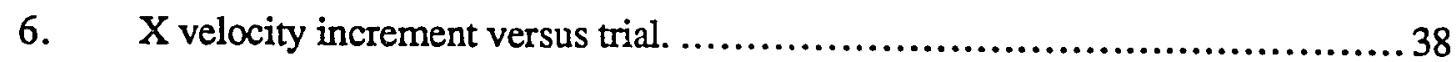

7. Mission duration 3-way interaction ......................................... 40

8. Velocity increment versus range........................................... 42

9. $\mathrm{X}$ velocity increment 2-way interaction..........................................4 43 
Quantitative and Qualitative Comparison Between Acceleration Control and Pulse Control in Spacecraft Docking

Adam Randall Brody

San Jose State University

Running head: SPACECRAFT DOCKING CONTROL MODE COMPARISON

Requests for reprints should be sent to Adam Randall Brody, Department of Psychology, San Jose State University, San Jose, California 95192 
Quantitative and Qualitative Comparison Between Acceleration Control and Pulse Control in Spacecraft Docking

Belatedly perhaps, but in our time there is widespread appreciation that the behavior of personnel in human-machine systems is as fundamental to system effectiveness as are hardware components. A neglect of workplace design will produce human error and degrade system effectiveness just as surely as will neglect of the design of a machine. Awareness of human factors in systems was heightened by the Three Mile Island incident which had human factors as its fundamental cause ... Awareness of the importance of human factors stretches back decades, growing gradually with the appreciation that human-machine systems do not work well if personnel and machines are not seen as partners in the system enterprise. (Adams, 1989, p. v)

While these premises may be self-evident to the human factors researcher, they are virtually ignored by the design engineers of advanced systems as the following quotation indicates.

A considerable amount is known about human beings and their behavior, although much more remains to be discovered. There is a pressing need for existing knowledge to be applied to the full, and for further research and development work to attract an appropriate level of support. We tend, as a society, to neglect the study of ourselves in our attempts to achieve our various goals. Nowhere is this policy more counterproductive than in the field of aviation, in which so much dependence is placed upon human performance for the safe and efficient achievement of our enterprises. (Edwards, 1988, p. 24)

This argument is readily extendible to the space environment.

Historically, in the design of large and complex systems such as aircraft, automobiles, and nuclear power plants, designers typically ignored human factors 
considerations or left them until too late in the design process to be useful. Controls and displays located outside reach and sight envelopes, inappropriate automation, and operating procedures designed without concern for man-in-the-loop considerations have plagued various industries and led to accidents causing the loss of many lives, vehicles, and other equipment. These accidents are highly visible in the aviation industry where two-thirds of the commercial aviation incidents and almost $90 \%$ of the general aviation incidents from 1959-1983 are believed to have been caused or influenced by human error (Nagel, 1988).

The Federal Aviation Administration (FAA), National Aeronautics and Space Administration (NASA), Department of Defense (DOD), and major airline manufacturers are actively involved with investigating the human factors environment of aircraft to identify the means to reduce the likelihood of human error. "At first sight, it is a strange professional link between the aerospace design engineer and the psychologist. Yet, since the days of the Wright brothers, there has always been a need for designers to take human factors into consideration to ensure the efficiency of any flying machine" (Birch, 1990, p. 45). Automation and crew coordination in addition to their relationships with flight procedures are currently important concerns.

While spaceflight does not put millions of civilians at risk every day, every minor incident receives tremendous attention by the media and the public. On-orbit flight activities put lives, missions, and billions of dollars of hardware in jeopardy. Current and future research into the manual control aspects of orbital flight will have tremendous payoffs in safety, reliability, efficiency, and productivity as space traffic increases in the upcoming Space Station Freedom era.

Spacecraft docking will be a commonplace activity in the era of the space station. Shuttle orbiters, orbital maneuvering vehicles (OMV) (or equivalent), and orbital transfer vehicles (OTV) will be docking to the station. Vehicles will also dock with satellites to 
return them to the station. Further into the future, vehicles will be docking in orbit around Mars, in lunar orbit, and on return to Earth orbit (Aldrin, 1990). Space Station Freedom will be used as a staging area for assembling and verifying the integrity of spacecraft en route to the moon and Mars. It will also be used as a repair shop for satellites and a platform for experiments and equipment. These activities will increase the docking traffic at the station, further justifying current research agendas. Current state-of-the-art computer graphics has improved real-time simulation and intensive and comprehensive human factors investigations with which researchers can study and better understand these activities.

In the 25 years since the first spacecraft docking, very little research describing human factors implications of spacecraft docking operations has been documented (Brody, 1987, 1989ab, 1990ab; Brody \& Ellis, 1990abc; Clark, 1965; Ellis \& Grunwald, 1989; Grunwald \& Ellis, 1988; Haines, 1987; Hartley, Cwynar, Garcia \& Schein, 1986; Meshcheryakov \& Minaev, 1976; Meshcheryakov, Sal'nitskii \& Nechaev, 1978; 1984; Novikov, 1968). Parameters of flight such as approach and impact velocities, braking gates, and control modes must be examined to uncover fundamental human factors capabilities and shortcomings concerning piloting spacecraft. Results from these studies will assist in expanding the operational flight envelope, and increasing safety and productivity. This study constitutes another in a series of experiments designed to accumulate a comprehensive database describing the manual control aspects of orbital flight.

Practical exploration by man of the nearest regions of space has already developed its own history which consists of separately distinguishable stages. During the first stage, mankind's curiosity concentrated mainly on the technical possibilities of overcoming Earth's gravity. During the next stage, the main focus of study centered on the survival of living organisms, including humans, in space 
using technical devices. The present stage primarily involves mankind's active work during prolonged spaceflights. Hence, in the short history of astronautics and cosmonautics, the centre of interest has been shifting away from the engineering sciences towards the biological, medical, and psychological sciences. (Terelak, 1989, p. 352)

Along with the psychological studies related to stress and workload are studies concerned with manual control and other areas in the general category of human factors. On Space Station Freedom, crewmembers will remotely operate vehicles, robots, and experiments subject to the peculiarities of zero-g, orbital mechanics, temperature extremes, and hard vacuum. Current research geared toward uncovering and exploring performance aspects of this environment could have large payoffs in the future.

The importance of manual control aspects of spaceflight operations, such as rendezvous and docking, was recognized early in the United States space program. After only three manned flights in the Mercury Program, the Technical Director of the Behavioral Sciences Laboratory, Aerospace Medical Research Laboratories, Wright-Patterson AFB concluded that "men can contribute greatly to the successful accomplishment of many types of space missions. ... the Mercury astronauts were able to manually compensate for equipment malfunctions and thereby complete missions which otherwise would have failed or terminated prematurely" (Grether, 1963, p. 79). As Gemini XII and Apollo XI astronaut Buzz Aldrin explains, "Manned orbital rendezvous was a vital field, because any way you cut it, if we were going to assemble large interplanetary spacecraft, we'd have to master the techniques of space rendezvous-bringing two or more separately launched spacecraft together in orbit. With computers we could reduce the blizzard of spherical geometry and calculus equations down to automated rendezvous procedures. But I'd seen enough autopilots malfunction during my flying career to realize that the spacecraft NASA 
Spacecraft Docking Control Mode Comparison

planned to use for Earth orbital lunar spaceflight would need some kind of manual backup" (Aldrin \& McConnell, 1989, p. 67). The Soviets also value the flexibility that manual control allows in "the capabilities of man to see three dimensions and to evaluate the situation better than a machine for flight conditions that have not been provided for by the program" (Meshcheryakov \& Minaev, p. 804). Gemini X and Apollo XI astronaut Michael Collins advocates manual control as follows: "was this not a noble cause, to build an autonomous capability, to allow a manned spacecraft to roam free of ground control, to compute its own maneuvers? Was not the very name of the game, in manned space flight, to put the pilots in control" (Collins, 1974, p. 169)?

Further justification for manual control may be found in the airline industry where "pilots still manually fly even the most highly automated aircraft, if only to maintain their flying skills in the case that they are called on if the automatics fail" (Nagel, 1988, pp. 293-4). Also, the adaptive capability that humans bring to control tasks adds further weight to the decision to use manual control instead of automation.

While automation is and will continue to be an important aspect of manned space flight,

It is unlikely that the pilot will be eliminated, any more than will the operator of a nuclear power plant. Our society believes that humans should have ultimate responsibility for control of complex systems even if inserting the human degrades overall system performance most of the time. The human is still the ultimate backup system. While machines that are overloaded fail abruptly, people degrade gracefully under excessive levels of workload. Thus it seems prudent to include human operators, even if only as the sub-system of last resort that can "pull the plug." Furthermore, there are also strong political forces to keep humans employed. (Kantowitz \& Casper, 1988, p. 183) 
The development "of rendezvous and docking procedures arose in the evolution of the U.S. space program once the initial exploratory phase (Mercury) had been successfully completed and missions became more ambitious. In the United States, the Gemini program was used to acquire these techniques and develop these technologies, and to give astronauts the practice they needed to get to the moon. Orbital rendezvous procedures were performed as the various Gemini craft tracked and approached their respective rendezvous targets. Gemini demonstrated that "precise flight-crew responses during orbital flight is [sic] critically dependent upon the fidelity of the simulation training received prior to flight' (Mueller, 1967, p. 1)" (Brody, 1987, p. 11).

While simulators were, and are, used extensively for procedure development and training, evidence of their use in human factors studies is virtually non-existent in the literature. Presumably, with the rush to get men to the moon and back before the end of the decade, time, money, and effort spent on such studies was not justifiable. Productivity benefits would not have been realized with the low economies of scale of 16 dockings (12 operational dockings in the Apollo program, three in Skylab, and one for the Apollo-Soyuz Test Project) over 10 years. By the end of the 1990s, however, space shuttle orbiters will be bringing crew and equipment to Space Station Freedom. By 2010, components of lunar bases and spacecraft will be brought to the station for checkout and assembly. Sorties will be made to investigate and repair satellites and other payloads. A small current investment geared toward a better understanding of manual control aspects of piloting docking maneuvers and other space operations could yield large payoffs in the future in terms of safety, reliability, productivity, and launch costs.

Another justification for the current interest in manual control aspects of spacecraft docking operations concerns the differences in on-board sensors and instrumentation between previous Apollo missions and future spacecraft dockings to the station. As Buzz 
Aldrin recalls the docking after ascent from the lunar surface, "Our radar and the computers on the two spacecraft searched for each other and then locked on and communicated in a soundless digital exchange" (Aldrin \& McConnell, 1989, p. 244). Current plans for Space Station Freedom omit this communication capability as well as a laser rangefinder that was proposed earlier. The rendezvous radar on the space shuttle is limited by a minimum operational range of 80 feet (Oberg, 1988). Ironically, rendezvous and docking operations will be harder to perform 20 years from now than they were 20 years ago because of reduced instrumentation and a paucity of information presented to the pilots.

In addition to discovering approach velocities, braking gates, control modes and other flight procedures that will increase safety, efficiency, and productivity, and decrease fuel use, research into the manual control aspects of space operations such as docking maneuvers has hardware implications. For example, there is a (not necessarily linear) tradeoff between the mass of a space station or satellite docking fixture and the amount (mass) of fuel that will be consumed by a vehicle docking with it. (Although current planning has vehicles berthing with the station by way of a manipulator arm, rather than docking, this tradeoff may still apply to satellite dockings.) Increased strength is paid for with an increase in docking fixture mass. More fuel is needed to control impact velocity when docking with a delicate structure than with a stronger, more massive one. Since launch costs are directly proportional to launch mass, hardware designers are incessantly endeavoring to reduce mass. However, over an operational lifetime, operational costs may be elevated as a result of the increased fuel consumption necessary to dock with a lighter, more fragile target.

Human factors studies can produce data concerning the fuel mass/approach velocity tradeoff. Flight simulator experiments can be conducted to analyze quantitatively the effect that the limit on impact velocity has on fuel consumption. In this way, the lifetime 
operational costs can be better understood and long-term benefits will not be sacrificed for short-term gains.

This is similar to line-oriented flight training (LOFT) with airlines, or missionoriented simulator training (MOST) in the Air Force, where different flight scenarios are simulated to examine and measure crew performance (Foushee \& Helmreich, 1988).

From the Gemini program, there is a historic example of uncertainties in fuel consumption requirements. Ratios of actual fuel consumption to theoretically minimum fuel consumption values varied from 1.52 to 4.28 for the ten rendezvous operations (Evans \& Czamik, 1967, p. 18). Clearly, mission planners need to understand this better in order to correctly allocate supplies for any given mission. Research into the manual control aspects of rendezvous maneuvers will help reduce both the absolute value and the variance of the actual/theoretical fuel consumption ratio.

A comprehensive study of the impact velocity effect on fuel consumption will also yield the effect impact velocity produces on mission duration. In the future, the desire to dock during orbital daylight, an increase in space traffic, and other constraints will make time management almost as important as fuel management. In January 1990, the Long Duration Exposure Facility (LDEF) was within weeks of tumbling out of control and deorbiting when the space shuttle crew rescued it. This is one example where time may be very important and a full understanding of the performance envelope for piloting may be necessary for the success of the mission. Studies can be performed to assess the impact of docking port location, number, and design on time and fuel consumption. In short, a comprehensive and extensive study of manual control aspects of spaceflight can produce many long-term savings of time, fuel, and launch costs while increasing safety and reliability. This is a timely research agenda to which greater resources and attention are due. 
Spacecraft Docking Control Mode Comparison

\section{Background}

\section{American Docking Experience}

The first spacecraft docking occurred in March 1966 during the Gemini 8 flight of Dave Scott and Neil Armstrong. Armstrong piloted the docking to the Agena target vehicle. "It was also 100 percent manually flown, not unlike mid-air refueling of airplanes, and it made us pilots feel good to hear Neil report that it had been easy, with no surprises" (Collins, 1974, p. 180). One half hour after docking, however, a malfunction in the Gemini attitude control system led to uncontrolled tumbling. Armstrong was able to null the motion with the hand controller; when he released it, the tumbling restarted. To simplify the problem, he backed the Gemini away from the Agena. This unfortunately aggravated the situation and the rotation rate increased to 300 degrees per second. He was ultimately able to recover control and stop the tumbling solely through manual control of the reentry attitude system. "The whole thing had lasted perhaps ten minutes, but they were the hairiest ten minutes in the space program so far" (Collins, p. 182).

"Neil was far and away the most experienced test pilot among the astronauts" (Collins, 1974, p. 317). His "Right Stuff" piloting skill was also required during the Apollo XI landing. He discovered that the designated landing location was too rough and he resorted to manual piloting to traverse the craters to a smoother spot. As Armstrong's crewmate Buzz Aldrin recalls,

At 500 feet, Neil was not satisfied with the landing zone. He took over manual control from the computer, slowing our descent from 20 feet per second to only nine, and then at 300 feet, to a descent of only three and a half feet per second... Neil did not like what he saw below. (Aldrin \& McConnell, 1989, p. xv) Ultimately, of course, the landing was successful, illustrating the flexibility of manual back-up without which the mission most likely would have failed. As Gordo Cooper said 
after his Faith 7 debriefing, "“. . man is a pretty good backup system ... "” (Aldrin \& McConnell, p. 101). Along with John Glenn's piloting skill in rescuing his Friendship 7 mission when his heat shield became dislodged, this incident helped to entrench the importance of manual control in the NASA mindset. Despite the flexibility and resourcefulness that crewmembers provide, it must be admitted that humans also supply additional sources of malfunction and error.

On Gemini X, in July 1966, John Young "finds [docking] as easy as Neil did on Gemini 8" (Collins, 1974, p. 211). Dockings were also performed on Geminis XI, and XII in September and November respectively. The crews of Apollos 9 and 10 practiced orbital docking operations with the Apollo configuration in 1969. (See Brody, 1987 for a detailed description of Apollo rendezvous and docking procedures.)

Even in the commercial airline industry, where there is far more collective piloting experience than in space, there is an apprehension of automation. Pilots have made such comments as, "In some cases the forces driving technology have caused the design of automated systems which compromise the ability of the pilot to fulfill his responsibilities for the safety of the airplane under his command" (Hoagland, 1984, p. 155). Since all NASA pilots come from a jet pilot background, comments such as these are relevant for the space program as well.

Soviet Docking Experience

Any discussion of spacecraft docking operations would be incomplete without mention of the accomplishments that the Soviets have had in this area. In 1991, the Soviets are inhabiting their eighth space station and as of July 1990 have had 35 successful autonomous dockings in space (Friedman \& Heinsheimer, 1990). Cosmonauts inhabit the Mir space station for many months at a time and unmanned vehicles automatically dock for resupply. Most of the information that follows was gleaned from the Almanac of Soviet 
Spacecraft Docking Control Mode Comparison

Manned Space Flight, by Dennis Newkirk (1990).

The Soviets began contemplating spacecraft docking operations when they realized these techniques were necessary for racing the Americans to the moon. Their first plan was an Earth orbital rendezvous (EOR) leading to a lunar fly-by. They were to use the same A2 boosters and launch facilities being developed for the Yoskhod program and other unmanned missions. Each mission would involve five launches. Soyuz V tankers would automatically rendezvous and dock and then fuel the Soyuz B rocket waiting in Earth orbit. The manned Soyuz would dock with the fueled rocket then ultimately be launched around the moon.

By 1964 they realized they were not developing the docking techniques fast enough to beat the Americans to the moon. They therefore decided to adopt a direct ascent profile, which involves launching directly from Earth to the moon, thereby eliminating the need for docking. After a series of failures, Zond 5B achieved the first lunar fly-by and return in September 1968. The spacecraft contained plants, turtles, flies, and worms. Some modifications were needed, however, as the returning capsule experienced between ten and sixteen g's, more than a human could endure. Zond 6 performed a similar mission in November but with $\mathrm{g}$ forces reduced by one-half. Technical difficulties delayed the December launch of Zond 7A (which most likely would have been manned) by one month allowing the US the first manned lunar fly-by with Apollo 8 in December.

The rush to the moon hurt both the Soviets and the Americans deeply. In January 1967, during a launch pad rehearsal for Apollo 1, Virgil 1. Grissom, Edward H. White, II, and Roger Chaffee died in a fire. Vladimir Komarov crashed to his death when the Soyuz 1 parachute shroud lines twisted in April 1967. These accidents delayed both the Apollo and Soyuz manned launches for over a year. "Apollo $I$ and Soyuz 1 taught the world that victories in space would be neither easy nor cheap" (Aldrin \& McConnell, 1989, p. 172). 
In October 1967, two Soyuz vehicles, modified after the Soyuz 1 tragedy, tested and perfected automatic docking operations. Kosmos (Cosmos) 188 was launched three days after Kosmos 186 and completed a rendezvous on the first revolution. Kosmos 186 became the active vehicle and docked with Kosmos 188, which was cooperatively maintaining a stable attitude. Cosmos 186 was the first Soyuz to have maneuvered in orbit. This was the first automatic docking and the first to be achieved by unmanned vehicles. Six months later, in April 1968, Cosmos 212 and Cosmos 213 repeated this procedure. Television cameras transmitted the undocking to ground control. These vehicles were essentially stripped down Soyuz spacecraft and the procedure they pioneered is similar to what is used today. A brief description follows.

Radar contact between the two spacecraft is established in the capture phase. Both vehicles align themselves to a common axis. The chaser vehicle closes with a range rate of about $2 \mathrm{~m} / \mathrm{s}$ at $350 \mathrm{~m}$. This is about six times faster than suggested by NASA's " $0.1 \%$ rule," which limits approach velocity to no greater than $0.1 \%$ of the range per second (Sedej \& Clarke, 1985; Oberg, 1988).

The target vehicle such as a space station then uses attitude control rockets to maintain orientation in the mooring phase. The chaser craft extends a probe to effect a soft docking. "The extended probe prevents the airtight seals of the two spacecraft docking collars from being damaged if the initial contact is hard or off center" (Newkirk, 1990, p. 65). The vehicles complete soft docking when small latches on top of the probe catch the center of the drogue.

"In the docking phase, the active ship reels its probe in and the ship's butt docking collars make an airtight connection" (Newkirk, 1990, p. 66). Latches in both collars hold the spacecraft together so electrical connections for communication and power may then be made. With Progress spacecraft, refueling connections also are consummated. Springs are 
Spacecraft Docking Control Mode Comparison

used for disengaging.

In October 1968, Colonel Georgiy Beregovoy attempted docking maneuvers in Soyuz 3. This was the first time the Soviets launched the passive target vehicle, Soyuz 2 , first as the U.S. did in the Gemini program. An automatic system guided Soyuz 3 from direct ascent to a range within 180 meters. Television cameras transmitted the image of the approaching target to the Soviets. This flight was intended to accomplish the first Soviet manned docking but all docking attempts failed (Newkirk, 1990). In one instance, ground control directed a maneuver calculated from data transmitted by the rendezvous antennae on each vehicle (Baker, 1982).

"Only 10 weeks after Soyuz 3, . . the shortest gap between non-related manned space missions to that time" (Clark, 1988, p. 50), the Soviets launched Soyuz 4. "The launch [sic] of Soyuz 4 and Soyuz 5 in January 1969 marked the first winter launch in the Soviet manned space programme, suggesting that the flights had to be urgently completed" (Clark, p. 51). Another descendent of the lunar fly-by mission was the first manned docking in January 1969 with Soyuz 5. After practicing almost 800 dockings in the simulator at Star City, Vladimir Shatalov accomplished an objective of the failed Soyuz 1 mission, i.e., the first Soviet manned docking. In Soyuz 4 he flew a manual approach to within a few kilometers of Soyuz 5. He then activated the automatic system, which reduced the range to 100 meters. Shatalov then regained control and docked during a live Soviet television broadcast. This docking set a precedent in that it did not occur during the first orbit. The Soviets announced the combined spacecraft "as the world's 'First Experimental Space Station"' (Clark, p. 51). Yevgeniy Khrunov and Aleksey Yeliseyev used the opportunity to perform the first transfer from one spacecraft to another.

The Soyuz was then modified for use as a space station ferry. Soyuz 10 and Soyuz 11 were the only flights with the original Salyut ferry. The most important change was the 
introduction of a crew transfer system, which precluded the necessity to go EVA to board the station.

The Soviets used Volga trainers to prepare for the docking operations. The Volga consisted of movable mockups of both Soyuz and Salyut mounted on rails. They would respond to commands made by the cosmonauts. A television view of the Salyut was presented to the Soyuz model's periscope system to give the crew a simulation of an actual approach (Clark, 1988).

While manual control has been relegated to a back-up position for unmanned supply vehicles, the Soviets have utilized manual control for manned dockings to space stations. This began with Soyuz 10, in April 1971, which brought the first crew of Vladimir Shatalov, Aleksey Yeliseyev, and Nikolay Rukavishnikov to Salyut 1. Salyut 1, mankind's first space station, was launched in April 1971 aboard the Soviet Union's most powerful space launcher, the D-1, and reentered the atmosphere in October. The Salyut assisted in the docking maneuver not only by maintaining attitude control, but "also made four orbit changes to match orbit with the approaching Soyuz" (Newkirk, 1990, p. 99). At a range of 180 meters, Shatalov took over control from the automatic system and performed a manual docking. Problems, most likely with the Soyuz, prevented the crew from boarding.

The Soviets and the Americans both advocate manual back-up for automatic docking maneuvers. However the Soviets only resort to the manual system upon failure of the automatic one, while the Americans tend to use manual control whenever it is available, not just as a back-up control mode. Such is the case with shuttle (and other advanced aircraft) landings where the mere existence of a manual control capability is cited as a justification for using pilot control instead of the automated system.

In an October 1970 meeting in Moscow, the Americans and the Soviets started 
formulating plans for the Apollo-Soyuz Test Project (ASTP). During a June 1971 meeting in Houston, "[Boris] Petrov expressed the preference of the Soviet Academy of Sciences for a joint docking flight employing the androgynous docking system" (Baker, 1982, p. 408). This could be accomplished either with a Soyuz docking with a Skylab/Apollo or an Apollo docking with a Salyut/Soyuz. The latter was established as the baseline mission.

In June 1971, Soyuz 11 was the next (and last) vehicle to dock with Salyut 1. The automated system reduced the range from $6 \mathrm{~km}$ to 100 meters. Georgi Dobrovolsky then took over control at a range of 100 meters and a velocity of $0.9 \mathrm{~m} / \mathrm{s}$. (This is nine times faster than suggested by the $0.1 \%$ rule.) By 60 meters, he reduced the range rate to 0.3 $\mathrm{m} / \mathrm{s}$. Dobrovolsky then completed the docking maneuver. The crew became the first to inhabit the first space station. After a record 24-day mission, the mission ended in disaster as the air escaped through an open valve 11 minutes before the craft reentered the atmosphere. Twelve pyrotechnic devices, used for separation, fired simultaneously rather than sequentially, releasing a seal on the spacecraft's pressure equalization valve. The atmosphere escaped in approximately 30 seconds while the cosmonauts were in the middle of a 60 second procedure to close the valve manually.

Shatalov consequently replaced General Nikolai Kamanin as head of the cosmonaut corp. A redesign of the station was necessary but since this would take longer than the Salyut's lifetime to complete, the station was deorbited. More than two years passed before the next manned mission.

The Soyuz Ferry was created to bring crews to Salyut space stations. It contained an automatic rendezvous and docking system known as Igla or "needle." As in earlier Soyuz docking missions, both spacecraft maneuvered actively. The Soyuz Ferry had its first manned flight, Soyuz 12, in September 1973. Since both Salyuts 1 and 2 failed in the previous year, this flight was able to only simulate transport to a space station. (Salyut 2 
most likely had an attitude control thruster stuck on and broke up in orbit before it was manned.)

Soyuz 13, launched in December 1973, was an independent mission and did not dock with a station. Soyuz 14 was the first operational use of the ferry and took the only Salyut 3 crew to orbit in July 1974. Automated rendezvous was used to reduce the range from 1000 meters to within 100 meters. Pavel Popovich then performed manual docking.

This procedure of manual control takeover at approximately 100 meters continued with Alesksei Gubarev on Soyuz 17, January 1975. Pyotr Klimuk performed similarly in May 1975 with Soyuz 18B.

Soyuz 19, better know as the Apollo-Soyuz Test Project, "was the first Soviet manned launch ever whose time was announced in advance and was the first to be televised live" (Newkirk, 1990, p. 140). Apollo was the active vehicle because of its greater fuel supply. The Soyuz merely had to maintain a fixed attitude toward the approaching Apollo, and match roll rates.

Soyuz 20 tested the Progress automated unmanned cargo transport systems in November 1975. Progress 1, however, did not fly until January 1978. The Progress, based on the Soyuz, carried twice as much rendezvous and docking instrumentation as the Soyuz Ferry. Also, a second video camera was mounted on the outside to give ground controllers a stereo view of the automatic docking. "Simultaneous transmissions of telemetry from Progress to Salyut and the ground enabled both the control center and the cosmonauts to assist with docking if necessary" (Baker, 1982, p. 524).

Progress 1 took two days approaching Salyut 6 as Soyuz 20 had done approaching Salyut 4. Manned spacecraft typically perform the approach in one day. "Since the Progress was unmanned, the crew did not retreat to the Soyuz during the docking as when the Soyuz 27 docked, they instead manned the station's controls ready to maneuver away 
Spacecraft Docking Control Mode Comparison

from the approaching Progress in case of a malfunction" (Newkirk, 1990, p. 179). Since the Progress was expendable, plume impingement upon it caused by an emergency Salyut separation maneuver was not a concern. None of the Progress missions through May 1988 had any docking problems although there were occasional problems with manned missions.

The Soyuz-T then replaced the Soyuz Ferry. It "included a new computer system and was claimed to be more automated than the earlier Soyuz variants; however, in flight the cosmonauts often had to take over manual control when the automatic systems apparently malfunctioned during docking manoeuvres" (Clark, 1988, p. 98). Soyuz T-1 flew in an unmanned configuration in December 1979.

In June 1980, the Argon docking computer flew its maiden launch on the first manned Soyuz T flight, Soyuz T-2. Argon selects which of several possible approaches to fly to a space station and then flies it with manual override capability. It similarly controls descent. Its operation required that the crew study computer programming. This training may have saved the mission as the automated docking system failed at a range of 180 meters from Salyut 6. "This was a problem which would be regularly repeated during Soyuz-T missions" (Clark, 1988, p. 120). Yuri Malyshev, a rookie, took over control and completed a successful manual docking. Aleksey Yeliseyev explained that the crew and flight controllers had not practiced the approach the computer selected so the crew decided to take over control to be better prepared in the event of an emergency. The crew claimed the automated system would have been successful if given the opportunity (Newkirk, 1990).

Soyuz 38, the seventh international crew, was launched in September 1980 with the first black cosmonaut. The automated system controlled not only the rendezvous but also the docking. The next manned flight, Soyuz T-3, was launched in November 1980. Its 
Argon automatic docking system performed the docking maneuver from a range of $5 \mathrm{~km}$.

The Soviets' Mir "Peace" space station evolved from earlier Salyut designs and was launched in February 1986. The station contains five docking drogues with a manipulator system that moves incoming modules from the forward port where they have docked to a side port. The Kurs "course" docking system was incorporated into the forward port. This eliminated the need for attitude control by the station during the docking maneuver (Newkirk, 1990). Clark (1988) claims the rear port also was outfitted with the Kurs system in addition to the old Igla system which would accommodate Progress freighters.

Mir's first crew was launched March 1986 on Soyuz T-15 with live Soviet television coverage. The Igla system controlled the approach to within 200 meters of Mir's aft docking port, which was compatible with Soyuz T and Progress. Leonid Kizim then flew around to the forward port, which was instrumented with the new Kurs system to be used with Soyuz TM and Star modules. The Soyuz was incapable of automatic docking at the forward port but the laser range finder that was first used on the Soyuz T-13 flight in June 1985 aided Kizim. Kizim completed a manual docking from an initial range of 60 meters. In May, the crew performed the first station-to-station transfer by flying over to Salyut 7 to reactivate it. Again, the hand-held laser range finder was used to generate range data. The automatic system was used from $5 \mathrm{~km}$ until Kizim took over manual control and docked. The crew returned to Mir at the end of June. After the crew used the Igla rendezvous system to reduce the range from 200 meters, Kizim took over control at a range of 50 meters from the rear docking port and maneuvered to dock at the forward port.

The Kurs rendezvous system was demonstrated in May 1986 with an unmanned Soyuz TM-1. This system does not require target vehicle transponders and can dock with a station at any relative attitude. It "makes contact with the station at a range of $200 \mathrm{~km}$ and docking lock-on begins at 20 to $30 \mathrm{~km}$ distance" (Newkirk, 1990, p. 313). Kurs presents 
Spacecraft Docking Control Mode Comparison

closing rate data from the docking radar to the cosmonauts.

On March 31, 1987, the Kvant "quantum" module, the first to be sent to Mir, was launched $1^{\circ}$ out of plane with Mir in an approach similar to that of Star modules. During its approach to Mir on April 5, the cosmonauts were suited up

in the Soyuz TM in case of a collision. The spacecraft started its approach at $17 \mathrm{~km}$ distance using the old Igla docking system. At 500 meters distance, the Kvant's forward docking camera was activated and the docking probe extended. When Kvant was only 200 meters from the station and preparing for final docking maneuvers, Flight Director Ryumin radioed to the cosmonauts that Kvant had lost its lock-on to Mir's docking transponders. .. . [Kvant drifted slightly and] was rotating slightly as it passed within 10 meters of Mir." (Newkirk, 1990, pp. 321322)

"The Kvant thrusters failed to slow down the module and it flew past Mir" (Clark, 1988, p. 155). Mission controllers spent several days analyzing the problem during which time the Kvant drifted to a range of $400 \mathrm{~km}$. Ground controllers brought Kvant back to the vicinity of Mir. The Igla automatic docking system was activated at a range of $22 \mathrm{~km}$. Lock-on to Mir's docking transponder signal was achieved; at a range of 1000 meters, the approach velocity was 2.5 meters per second. (This is 2.5 times the rate suggested by NASA's $0.1 \%$ rule.) The relative velocity was decreased to .32 meters per second at 26 meters ( 12.3 times the $0.1 \%$ rule rate of .026 meters per second). Soft docking was achieved within 21 minutes of Igla lock-on.

During the docking of Progress 33 in November 1987, the Soviets experimented with new station orienting procedures since the Igla system, used by the Progress, required active maneuvering by the target vehicle. Typical fuel expenditures for docking a Progress to Mir were approximately $192 \mathrm{~kg}$ using the old system. "The new Igla procedure reduced 
Spacecraft Docking Control Mode Comparison

this amount to about $82 \mathrm{~kg}$ " (Newkirk, 1990, p. 322).

The first launch of the Progress M, a modified Progress, occurred in August 1989. It has an increased on-orbit stay time, "has an improved automated docking system and also is able to transfer unused fuel to the space station" (Rains, 1990b, p. 8). The Progress M also possesses a return capsule, which was successfully tested on mission Progress M5, in November 1990 (Kiernan, 1990).

Docking Failures.

Despite their great experience with docking both manned and unmanned spacecraft, the Soviets have had several failures during docking maneuvers. Failures occurred with Soyuz 15 in August 1974, Soyuz 23 in October 1976, Soyuz 25 in October 1977, Soyuz 33 in April 1979, and Soyuz T-8 in April 1983.

The failure of Soyuz 15 to dock with Salyut 3 was due either to a repeated system failure to initiate the manual control phase at a range of 100 meters (Clark, 1988), or, "the automatic system malfunctioned twice, pushing the ship out of control with excessive engine burns while only 30 to 50 meters from the station" (Newkirk, 1990, p. 128). With a limited battery and fuel supply, the vehicle had to de-orbit when the docking failed.

In October 1976, Soyuz 23 was aborted because of a malfunction in the automatic docking system. This occurred before the range of the Soyuz to the Salyut 5 station was reduced to 100 meters. Since the crew of Vyacheslav Zudov and Veleri Rozhdestvenski were trained to take over from 100 meters, but not before, the crew were forced to land as soon as possible. The manual back-up mode was not extensive enough to save this mission. As Tass reported, "the spaceship Soyuz 23 was put into the automatic regime for the approach to Salyut 5. Docking with the Salyut 5 station was cancelled because of an unplanned operation of the approach control system of the ship" (Clark, 1988, p. 74). Viktor Grobatko flew a successful docking of Soyuz 24 in February 1977 after 
Spacecraft Docking Control Mode Comparison

taking over control at a range of 80 meters. The Soviets' success was short-lived, however, as failure plagued Soyuz 25 in October that year. Vladimir Kovalyonok began the docking maneuver from 120 meters but five docking attempts to the Salyut 6 station failed due to a faulty docking fixture on the Soyuz. As the news release stated, At 07.09 [sic] Moscow time today [10 October] the automatic rendezvous of the Soyuz 25 ship and the Salyut 6 station was begun. From a distance of 120 metres, the vehicles performed a docking manoeuvre. Due to deviations from the planned procedure for docking, the link-up was called off. The crew has begun making preparations for a return to Earth. (Clark, 1988, pp. 104-5)

While soft docking was achieved, hard docking enabling electrical connections to be made was not. This failure resulted in the prohibition of all-rookie crews; Romanenko and Ivanchenkov from the all-rookie back-up crew were each paired with veteran cosmonauts.

Soyuz 33, with the fourth international crew-Bulgaria, was launched in April 1979. The Igla system was implemented at a range of $9 \mathrm{~km}$. While approaching a range of $1 \mathrm{~km}$ from Salyut 6, the Soyuz automatically fired its main engine for only three of its scheduled six seconds and caused tremendous shaking. The second attempt with Igla also failed when it immediately shut down the engine. As Tass reported, "During the process of approach there occurred deviations from the regular mode of operation of the approach correcting propulsion unit of the Soyuz 33 spacecraft, and the docking of the craft with the Salyut 6 was aborted" (Clark, 1988, p. 114). The Soviets determined the problem to reside in the Soyuz main engine which was terminating thrust upon a failure to attain normal combustion pressure. This was the first on-orbit failure of the Soyuz propulsion system. The crew returned to Earth without docking. This amounted to the second failed visit to a Salyut for Nikolay Rukavishnikov, the Soviet's first civilian commander. The Soyuz 32 crew in Salyut 6 did not receive supplies until Progress 6 brought them in May. 
Another failure occurred in April 1983 with the aborted Soyuz T-8 mission. Although the launch shroud accidentally removed the rendezvous radar antenna, mission controllers decided to violate their own rules and let Vladimir Titov attempt an optical rendezvous from $10 \mathrm{~km}$. This had never been done before by the Soviets and was particularly risky since Titov later claimed he had not previously trained for manual approach and docking. Flight directors assisted Titov by computing the range rate after Titov reported Salyut size estimates. After a range of 330 meters was passed, the Soyuz slipped out of contact with the ground. Without his range rate source, Titov was not sure of his closing rate. Although he was able to reduce his range to 75 meters with the aid of the Soyuz's floodlight, he approached at too high a velocity and fearing a collision, fired thrusters to change orbits and abort the docking (Newkirk, 1990).

There had been ten manned launches to Salyut 1, Salyut 3, Salyut 4 and Salyut 5. Of these one had failed to reach orbit (Soyuz 18-1), two had failed to dock with their Salyuts (Soyuz 15, Soyuz 23), one had docked but the crew had been unable to transfer to their Salyut (Soyuz 10) and one crew had perished during their return to Earth (Soyuz 11). This left the Soviets with a 50 per cent success rate, if we deem Soyuz 21 as a successful mission even though it was terminated earlier than planned. ... During 1977-1981 there were 16 Soyuz spacecraft launched towards Salyut 6 and of these only one failed to dock (Soyuz 33) and one docked but the crew could not transfer (Soyuz 25); additionally, there were 4 launches of Soyuz-T craft, 12 launches of Progress craft and the Cosmos 1267 mission - all of which successfully docked with Salyut 6 . For Salyut 6 the success rate was 94 per cent. (Clark, 1988, pp. 126-7)

\section{Docking Recoveries.}

Not all failures resulted in the loss of the mission. During the Soyuz T- 6 mission in 
Spacecraft Docking Control Mode Comparison

June 1982, Vladimir Dzhanibekov rescued the docking with a manual maneuver after the automatic system failed. After turning the spacecraft around to perform the braking maneuver, at 900 meters from Salyut 7, the Argon computer failed and would not realign with the station. Dzhanibekov disconnected the computer and maneuvered the Soyuz along all three axes to resume pointing at the station. His successful docking from such a far range under manual control was a major achievement (Newkirk, 1990). The regular failure of the Soyuz-T system during final approach was usually followed by manual recovery and presumably led to computer improvements in Soyuz-TM (Clark, 1988).

Vladimir Dzhanibekov was no stranger to docking operations as this was his third. After five flights (he is the first, and as of 1986 still the only, cosmonaut to fly more than three missions), he is the Soviet Union's most experienced cosmonaut. Dzhanibekov served as back-up commander to Alexei Leonov for ASTP but did not fly until January 1978 with Soyuz 27 when he achieved the first double docking with a manned space station. In March 1981 he flew his second flight in Soyuz 39 with Jugerdemidiin Gurragcha. In July 1984, on Soyuz T-12, he accompanied Svetlana Savitskaya in the first extra-vehicular activity (EVA) by a female (Hillyer, 1986).

As prime commander of the Soyuz T-13 mission, Dzhanibekov had the privilege of testing a new manual docking system in June 1985. The primary purpose of this flight was to rescue Salyut-7 after it had lost all power and was rolling aimlessly in space. As Dzhanibekov says,

There were great difficulties with preparation for docking with this object. The station seemed to us as a dead space object and nothing more. And specialists were afraid that it would rotate in space at too high a speed in three axes. So we had to train and to find out this optimum way to maneuver around the station to find the best light conditions of the Sun. And of course to train our hand ... everything 
Spacecraft Docking Control Mode Comparison

had to be done manually. (Hillyer, 1986, p. 17)

Equipped with a laser rangefinder, Dzhanibekov compared the measured range to Salyut-7 with the range computed by his spacecraft. At $10 \mathrm{~km}$, Dzhanibekov interrupted the automated approach to input Salyut 7 attitude data into the Soyuz docking computer. The automatic approach resumed until " $3 \mathrm{~km}$ distance, at a rate of 12, and later 6 meters/second when Dzhanibekov took control" (Newkirk, 1990, p. 270). At three km, "there started to be a difference between our measurements and the radar-calculated data. So I had to take the handles and step in to direct manually" (Hillyer, 1986, p. 17). "At 2 $\mathrm{km}$, the crew used a new optical guidance system, hand-held laser range finder and a night vision instrument, to see and measure distance to the station" (Newkirk, p. 270). At a range of 200 meters, Dzhanibekov nulled the approach velocity because the sun was behind the station making visibility poor. For 10 minutes he circled the station on damage patrol. Then, in a roll-matching maneuver, he docked with the station. "(Later Dzhanibekov would say, 'Docking is like driving a seven-ton truck with fragile freight on an icy road into a narrow gate at the end of this road')" (Kramer, 1990, p. 57). The docking was successful and Dzhanibekov has similar opinions about manual control as Buzz Aldrin: he shares Aldrin's skepticism about automated systems and claims that manual control gives the ability to "operate in [a] wider range" (Hillyer, p. 18).

Salyut 7 reentered on February 7, 1991 ("Soviet Salyut 7," 1991, p. 15). The Salyut 7-Cosmos 1686 was the largest object (43 tons) to reenter since Skylab reentered on July 11,1979 . The Salyut's demise was accelerated by a peak in solar flare activity in 1989.

Admittedly, one of the main reasons for manual control is emotional or political; namely, pilots would rather fly than watch. However, the successful rescues mentioned previously would not have been possible without human intervention. 
Another recovery was made with Soyuz TM-5 (the thirteenth international crewBulgaria), in June 1988. Although the Kurs system malfunctioned during the final approach, flight controllers diagnosed the problem and a successful docking was completed within two days of the launch.

In June 1990, a docking recovery was achieved with an unmanned vehicle. Docking of the Kristall module with the Mir space station was automatically aborted when a Kristall computer discovered a malfunction in one of its attitude control thrusters. Ground controllers used a backup set of thrusters to complete the docking operation successfully (Rains, 1990a).

\section{Current Study}

Docking maneuvers have traditionally been simulated and ultimately performed in a "pulse" control mode. That is, thrusts of a prescribed magnitude (duration) were commanded by deflection of a hand controller, regardless of deflection angle or duration. Subsequent burns were possible only after release of the joystick to its rest position. NASA space shuttle pilots and orbital maneuvering vehicle (OMV) pilots currently are instructed to use such pulse control presumably for fuel consumption and/or safety reasons (Oberg, 1988; Sedej \& Clarke, 1985).

Nevertheless, all previous experimentation in this series involved acceleration control in which thruster commands were sent for the duration of the deflection (Brody, 1987, 1988, 1989ab, 1990a; Brody \& Ellis 1990abc). (In temporal terms, this is analogous to the control mode in an automobile, although in automobiles, energy must be expended constantly to overcome friction.) Previous experimentation by others has shown that "With an acceleration control system, [as used with spacecraft,] onoff [sic] control is the quickest way of correcting an error in position" (Poulton, 1974, p. 135). Also, "in compensatory tracking with an acceleration control system, onoff [sic] control is the 
optimal strategy provided the man knows how to use it" (Poulton, p. 371). Clearly there is historical evidence justifying acceleration control and there is no reason why pilots cannot be taught how to make the best use of acceleration control. This study involved a formal comparison between pulse control and acceleration control to determine which is better in regard to fuel consumption, mission duration, safety, and other considerations.

In the current study, the trials were organized in APPA and PAAP orders where A denotes a series of 18 simulated dockings using acceleration control and $\mathrm{P}$ corresponds to a series with pulse mode. Subjects who began with acceleration mode, continued with two blocks of pulse mode before returning to their final block with pulse mode, i.e., APPA. Subjects beginning with pulse mode did the opposite, i.e., PAAP.

One of the intents of this format was to unearth any potential asymmetrical transfer as has been found in other control mode comparisons. Asymmetrical transfer would be evident if a control mode $x$ order (mode $x$ first mode) effect were found (Poulton, 1974). It specifically means the effect of practice with one control mode on subsequent performance with the other control mode is different for the two possible sequences of activity, i.e., a PA sequence vs. an AP sequence. This would occur, for example, if subjects who began with pulse mode achieved lower mission duration values when they later flew in acceleration mode than those who began with acceleration mode and followed with pulse mode. Such a finding would be useful for identifying which control mode to use for training as opposed to flight. Alternatively, a control mode $\mathrm{x}$ range interaction would indicate which mode was better depending upon the initial range of the mission. Preliminary data suggests that learning is easier in pulse mode but better performance characteristics are achieved with acceleration control. Asymmetric transfer effects can also cloud comparison of control modes since the subjects asymptotic performance may not be accurately reflected by the experimental data. 
Spacecraft Docking Control Mode Comparison

Method

Subjects

Nine commercial airline pilots served as paid test subjects in this study. Pilots were used with the expectation that the manual control, attention, discipline, and intelligence skills typically associated with pilots would make them superior subjects. In purely subjective terms, however, they performed no better than any other previous group of simulated spacecraft pilots. For example, neither learning nor performance was consistently better than with previous groups of subjects.

All of the subjects were rapid learners and preferred pulse control to acceleration control. One subject's data were dropped from analysis because he did not complete all of the trials within one session as all of the others had. Another subject's data were disregarded because, due to experimenter error, he received his trials in an ABAB order rather than ABBA. This left the data from nine subjects, four who began with acceleration control and five who began with pulse control. Furthermore, the medians of the dependent values of five of one subject's trials with the same mode, block, range, and trial were substituted for the values for the one trial in which he received an incorrect starting range in a make-up trial.

Apparatus

The Space Station Proximity Operations Simulator at NASA Ames Research Center simulates a proximity operations control room on a space station. A PDP 11/60 computer in conjunction with an Evans and Sutherland PS II picture system drove three windows. These windows displayed a simulated view out the $-\mathrm{V}$-bar (negative velocity vector) of a space station in a 270 nautical mile circular orbit around the Earth. An accurate star field was visible with all stars down to the fifth magnitude (Haines, 1986; Lee \& Wu, 1987).

A three-degree-of-freedom displacement hand controller was used to remotely 
command thruster firings of a simulated orbital maneuvering vehicle (OMV). Hand controller movements fore and aft $(+X)$, and left $(+Y)$ and right, commanded the OMV to move in similar directions. Downward $(+Z)$ commands were sent by a clockwise twisting of the hand controller while upward commands required a counterclockwise twist. The subjects used three buttons on the hand controller to control the thruster characteristics for each coordinate axis independently. Thruster values for pulse (acceleration) mode were toggled among $1.0,0.1$, and $0.01 \mathrm{~m} / \mathrm{s} / \mathrm{s})$. The subjects used a joystick-mounted trigger button to begin each trial.

A head-up display (HUD) containing flight data was superimposed on the center window. Mission duration, velocity increment (Delta V), 3-axis range and rate, slant range and rate, and thruster values were presented to the subjects (see Figure 1) (Brody, 1988). Procedure

Test subjects performed simulated docking maneuvers of the OMV to a space station from three different ranges on the -V-bar. Each subject used both control modes in blocks of 18 docking attempts consisting of 3 ranges $(50,100,150 \mathrm{~m})$ x 6 repetitions in a latin squares configuration. For the data presented here, five subjects began with acceleration control and 4 began with pulse control. A test session consisted of four blocks, two with each control mode. The blocks were arranged in an ABBA order. This yielded a total of 72 trials for each subject. Experimentation required about 5 hours per subject.

Before data collection began, subjects practiced until they achieved 15 successful dockings with each control mode. Success was operationally defined as being in the right place at the right velocity: up/down and right/left ranges and rates no greater than $0.23 \mathrm{~m}$ and $0.06 \mathrm{~m} / \mathrm{s}$, respectively, and forward velocity no greater than $0.15 \mathrm{~m} / \mathrm{s}$ at a range of $2 \mathrm{~m}$ (NASA Lyndon B. Johnson Space Center, 1985). At the end of each block, subjects 


\section{Spacecraft Docking Control Mode Comparison}

repeated unsuccessful trials to achieve a complete set of 72 successful simulated dockings.

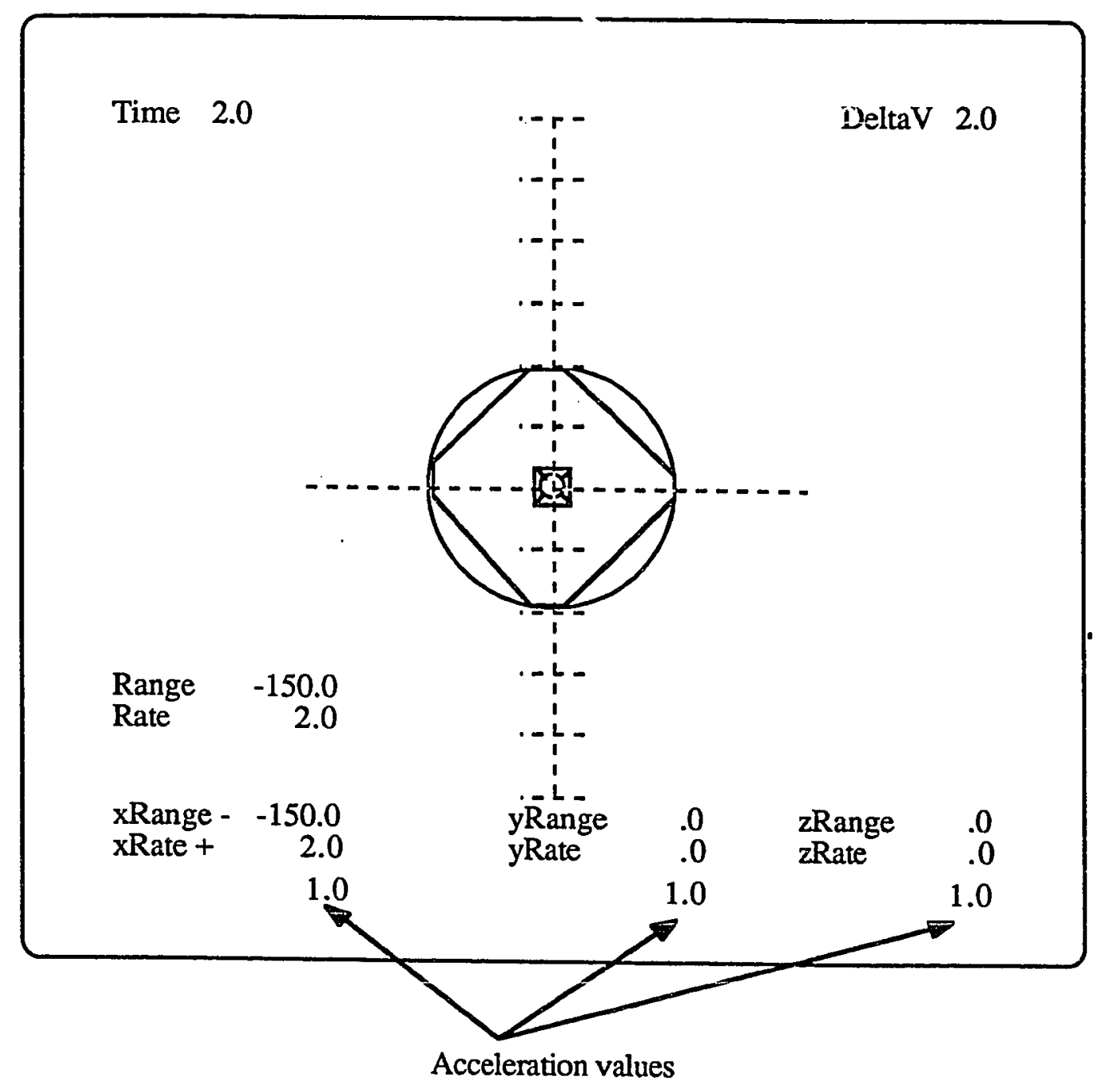

Figure 1. Head-up display. 
At the end of each trial, performance data were displayed to the subjects. Threeaxis range and rate data on impact were presented in addition to total mission duration and fuel consumption. Any and all violations of the docking constraints were highlighted.

Results

Five-way mixed analyses of variance (ANOVA) with one between factor (first mode), and four within factors (mode, block, range, and trial) were performed on the data. All statistically significant effects at the .05 level are summarized in the following table. (See Table 1.) "Trial" refers to consecutive presentations of identical experimental treatments. "Mode," "range," and "block" are the same for a group of six trials. "Block" distinguishes between the two groups of 18 consecutive trials with the same control mode. The blocks were designated first half and second half.

Control mode produced statistically significant, but opposite, effects on mission duration and velocity increment. Mission duration was lower with pulse mode while fuel use measured as velocity increment was lower with acceleration mode. Subjects used more fuel to travel faster with pulse mode than with acceleration mode. As in more terrestrial, linear environments, greater velocities leading to reduced mission durations are paid for by increased fuel consumption. Although the subjects were trained to criterion, further training could most likely be used to reduce mission duration and/or fuel consumption levels. These results give some indication of what the underlying tendencies are before extensive training. These data appear in figures $2 \mathrm{a}$ and $2 \mathrm{~b}$.

Mission duration, velocity increment, $X$ velocity increment, $Y$ velocity increment, and $Z$ velocity increment all increased with range. Figure 3 illustrates the mission duration data. Subjects commanded the OMV to "fly" faster from further distances as indicated by a slope of less than unity on the mission duration versus range plot. (Note that the ordinate axis does not begin at 0 .) These higher average velocities were paid for by increased fuel 
Table 1

Significant effects from ANOVA

\begin{tabular}{|c|c|c|c|}
\hline Dependent Variable & Significant Factor & $\mathrm{F}$ & $\mathrm{p}$ \\
\hline \multirow[t]{4}{*}{ Mission Duration } & Mode & 12.544 & .0094 \\
\hline & Range & 24.156 & .0001 \\
\hline & Trial & 4.143 & .0046 \\
\hline & Mode $*$ Block $* 1$ st & 5.835 & .0464 \\
\hline \multirow[t]{4}{*}{ Velocity increment } & Mode & 6.431 & .0389 \\
\hline & Range & 34.57 & .0001 \\
\hline & Block * range & 5.792 & .0147 \\
\hline & Mode $* \mathrm{bl} * \mathrm{r} * \mathrm{tr} * \mathbf{I s t}$ & 2.100 & .0357 \\
\hline \multirow[t]{4}{*}{$\mathrm{X}$ Velocity increment } & Block & 7.118 & .0321 \\
\hline & Range & 31.344 & .0001 \\
\hline & Triai & 2.653 & .0390 \\
\hline & Block x range & 5.864 & .0141 \\
\hline
\end{tabular}




\section{Spacecraft Docking Control Mode Comparison}

\begin{tabular}{llll} 
Y Velocity increment & 1st Mode & 31.523 & .0008 \\
& Range & 6.861 & .0084 \\
& Range * 1st Mode & 6.721 & .0090 \\
& Mode * Range * Trial & 2.308 & .0208 \\
& Mode * $\mathrm{r}$ * tr * 1st & 2.287 & .0219 \\
& Mode * bl * ${ }^{*}$ Trial & 1.984 & .0481 \\
& Mode * bl * $\mathrm{r}^{*} \mathrm{t} * 1 \mathrm{st}$ & 2.018 & .0441 \\
& & & \\
Z Velocity increment & Range & 4.142 & .0429 \\
X Rate & Trial & 2.759 & .0334 \\
& & & \\
\hline
\end{tabular}


Spacecraft Docking Control Mode Comparison

Mode Main Effects
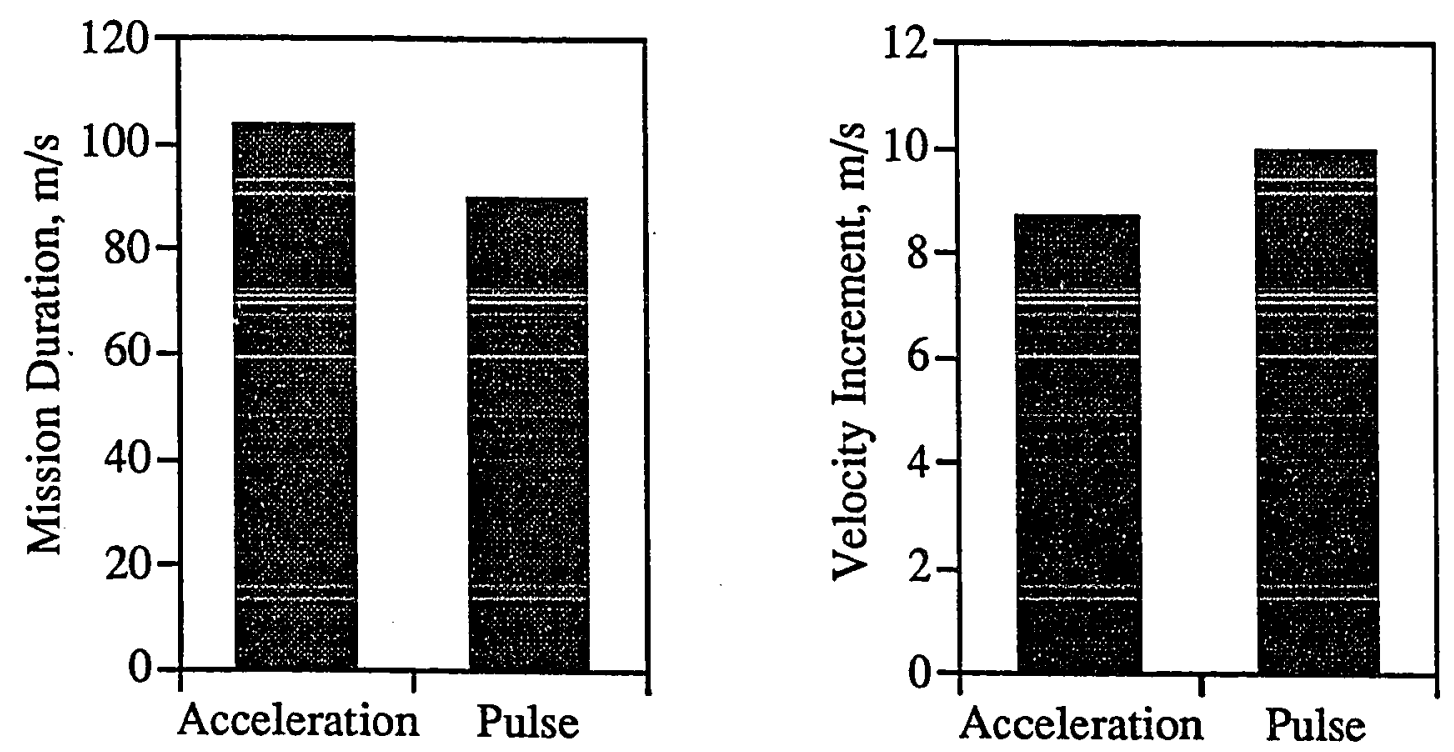

Figures 2a, 2b: Mode main effects. 
Spacecraft Docking Control Mode Comparison

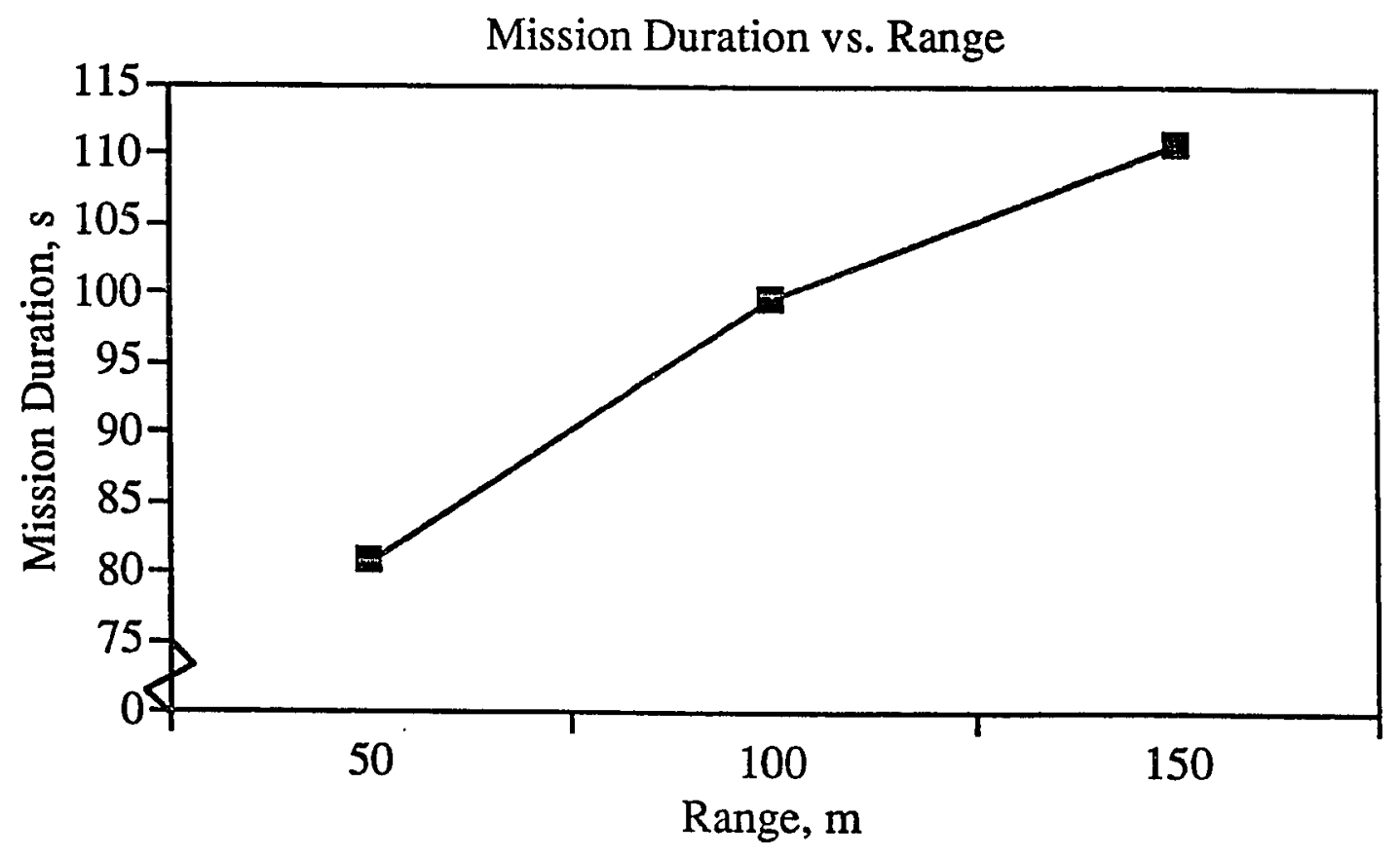

Figure 3: Mission duration versus range. 
Spacecraft Docking Control Mode Comparison

consumption (see Figure 4).

The variation of $Z$ velocity increment, the cumulative total of thrusts used to correct for orbital mechanics effects, with range is also shown in Figure 4. This increase is due to the increase in mission duration with range. More fuel was required to compensate for the orbital mechanics effects when there was more time for them to operate. $\mathrm{X}$ velocity increment and $\mathrm{Y}$ velocity increment also increased with range.

A particularly interesting range effect was the one reflected in $Y$ velocity increment. The y-axis was the out-of-plane component. Since motion along this axis is uncoupled from motion along the other two axes, an object with zero y displacement with respect to a target needs no attention. Although the trials in this study were initialized so that no thrusts along the $y$-axis were required, accidental commands were produced from which recoveries had to be made to achieve a successful docking. Most likely, the longer mission durations associated with the greater initial ranges provided the subjects with more time in which to cause a y disturbance.

Even though the subjects practiced to criterion prior to experimentation, a practice effect in which subjects improved with experience was still evident in the data. Mission duration decreased with trial in a typical learning curve format as in Figure 5. Surprisingly, $\mathrm{X}$ velocity increment increased with experience as illustrated in Figure 6. This effect is most likely due to subjects becoming more comfortable with the simulated docking maneuver and consequently using more fuel to travel faster. This also influenced the mission duration data.

The $\mathrm{X}$ velocity increment data also demonstrated a block effect. Fuel consumption along the $\mathrm{x}$-axis was less at the beginning of testing than at the end. Values from the first 
Spacecraft Docking Control Mode Comparison

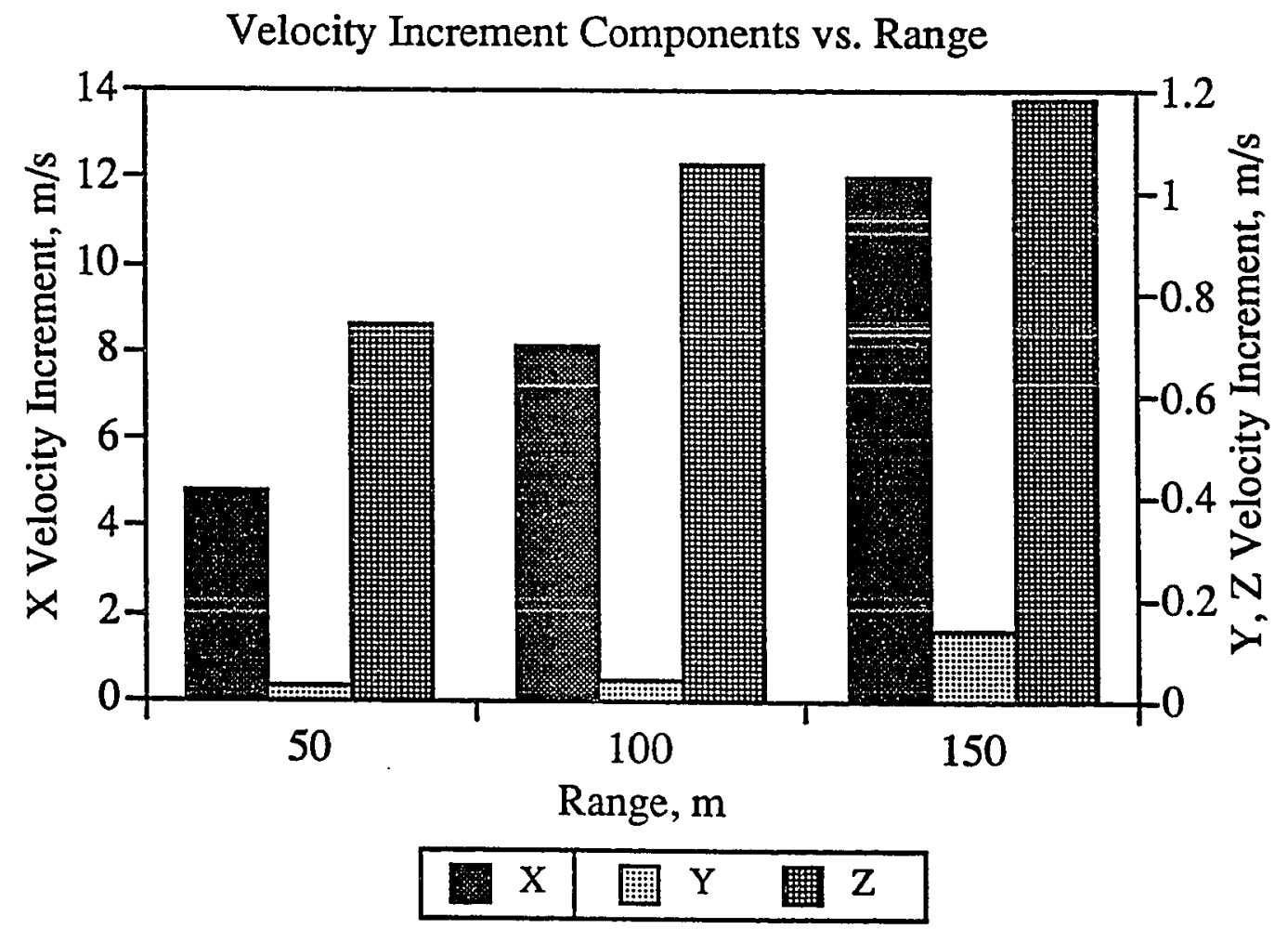

Figure 4: Velocity increment components versus range. 
Spacecraft Docking Control Mode Comparison

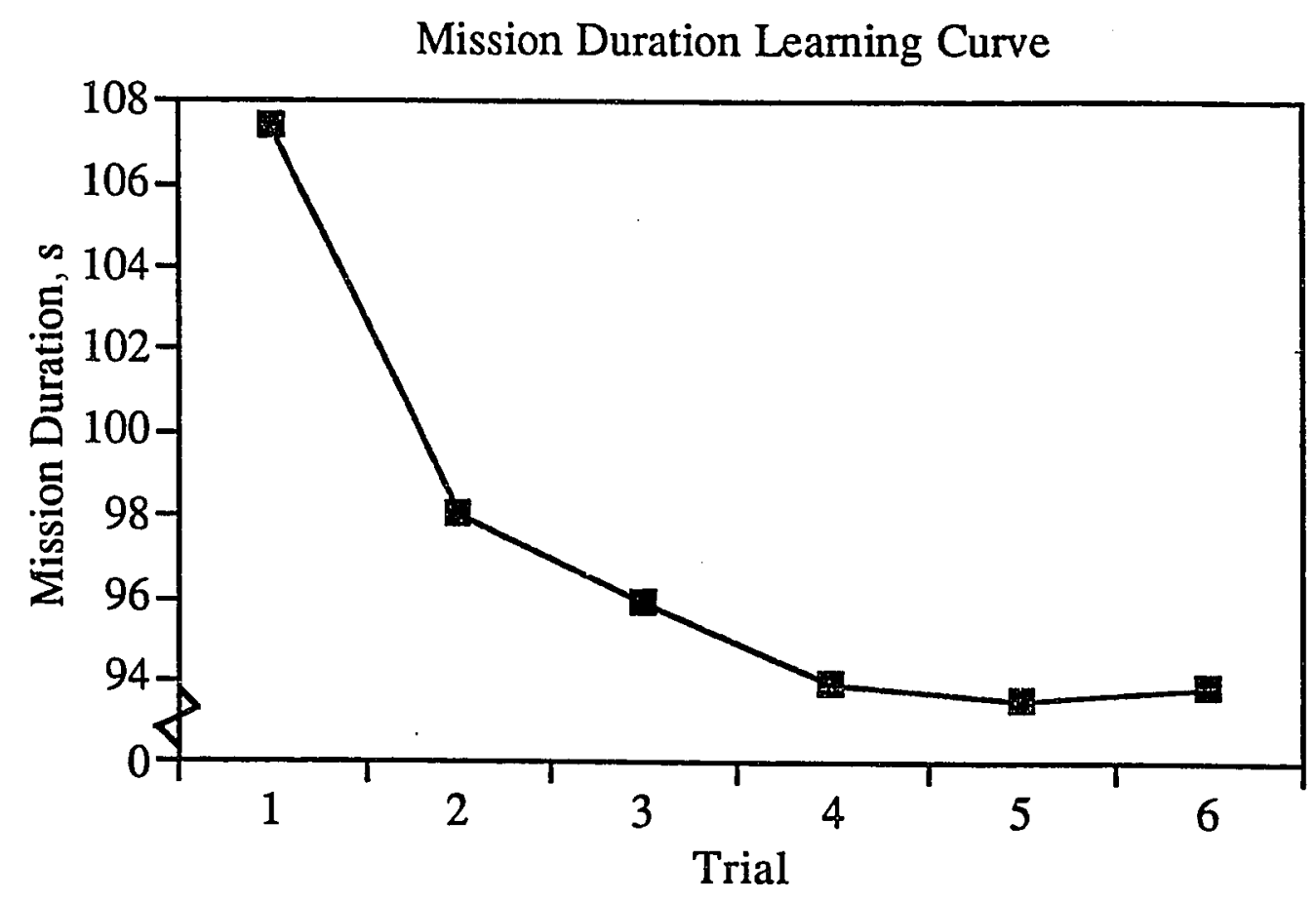

Figure 5: Mission duration versus trial. 
Spacecraft Docking Control Mode Comparison

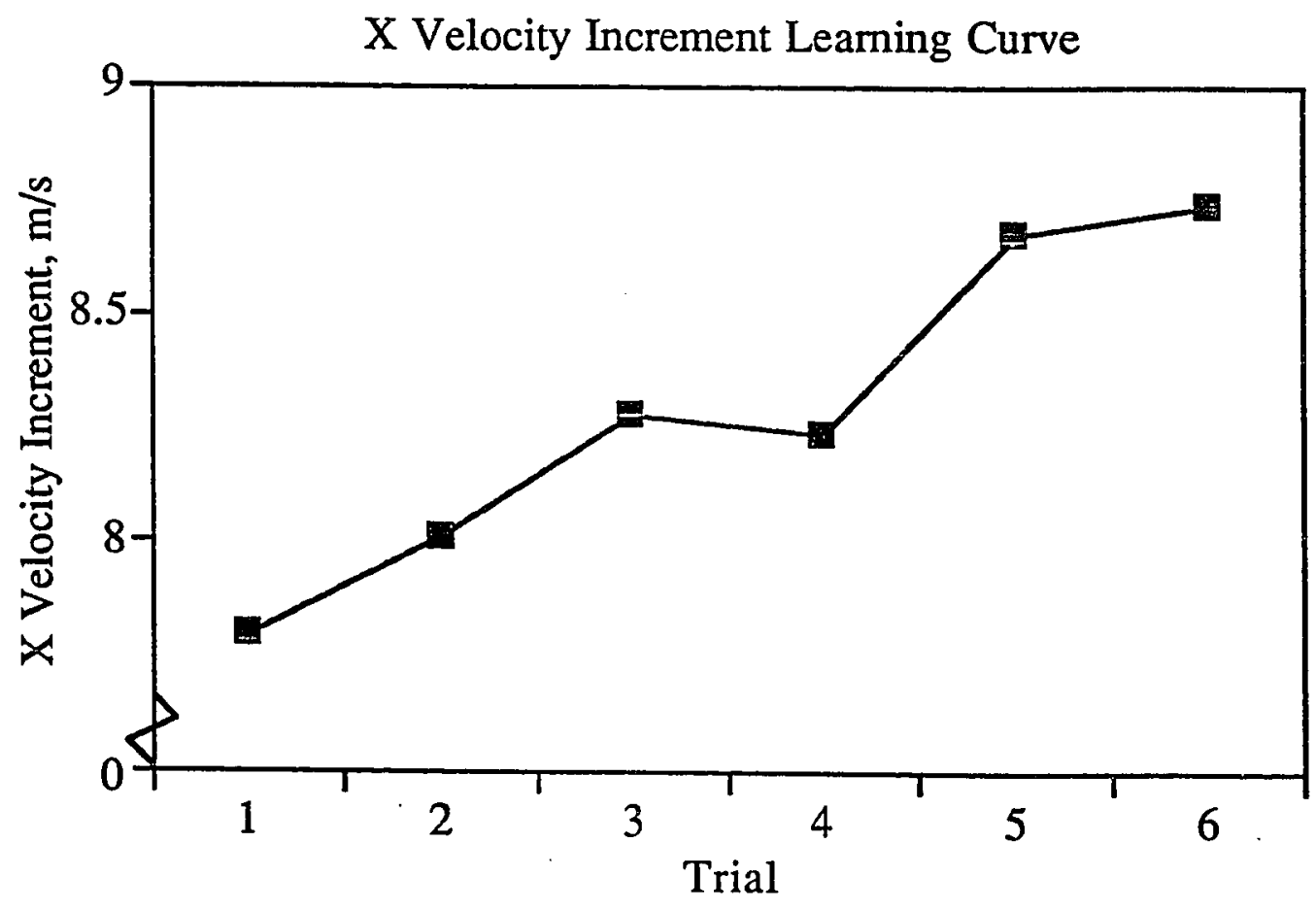

Figure 6: $\mathrm{X}$ velocity increment versus trial. 
18 trials with a mode were less than those from the second half with means (SDs) of $7.7(4.9)$, and $8.9(6.1) \mathrm{m} / \mathrm{s}$ for the first half and second half respectively. This effect is similar to the trial effect with fuel consumption and velocity increasing with experience. It shows the trend following experience not only within blocks as with the trial effect but also between blocks as mentioned here.

Analysis of the data also revealed three 2-way interactions, two 3-way interactions, two 4-way interactions, and two 5-way interactions. Higher order effects are typically difficult to decipher. Of particular interest are the ones containing a mode or first mode term.

The mode $\mathrm{x}$ block $\mathrm{x}$ first mode interaction for the mission duration data appears in Figure 7. It shows that the main effect relationship between the modes, namely, the mean for mission duration in pulse mode is less than the acceleration mean only holds for the first half of the data. In the second half of the data, the pulse data for subjects who began in acceleration mode has the same mean as the data from those subjects who began in pulse mode.

The error bars indicate that the data for blocks 2 and 3 for both sets of subjects are not distinct. Essentially, mission duration values for the middle two blocks are the same for both modes. There is also no statistically significant distinction between the data from blocks 1 and 4 in the PAAP group. However, the mission duration mean for block 4 is lower than that for block 1 in the APPA group.

No improvement in mission duration was found for the subjects who began with pulse mode while the data from the acceleration first group display learning. These data support the experimental hypothesis that experience in pulse mode helps performance in acceleration mode. Asymmetrical transfer was found in that the mode transitions could not be predicted solely from the main effect. Both acceleration means in the PAAP group were 
Spacecraft Docking Control Mode Comparison 40

First Mode x Block x Mode Interaction

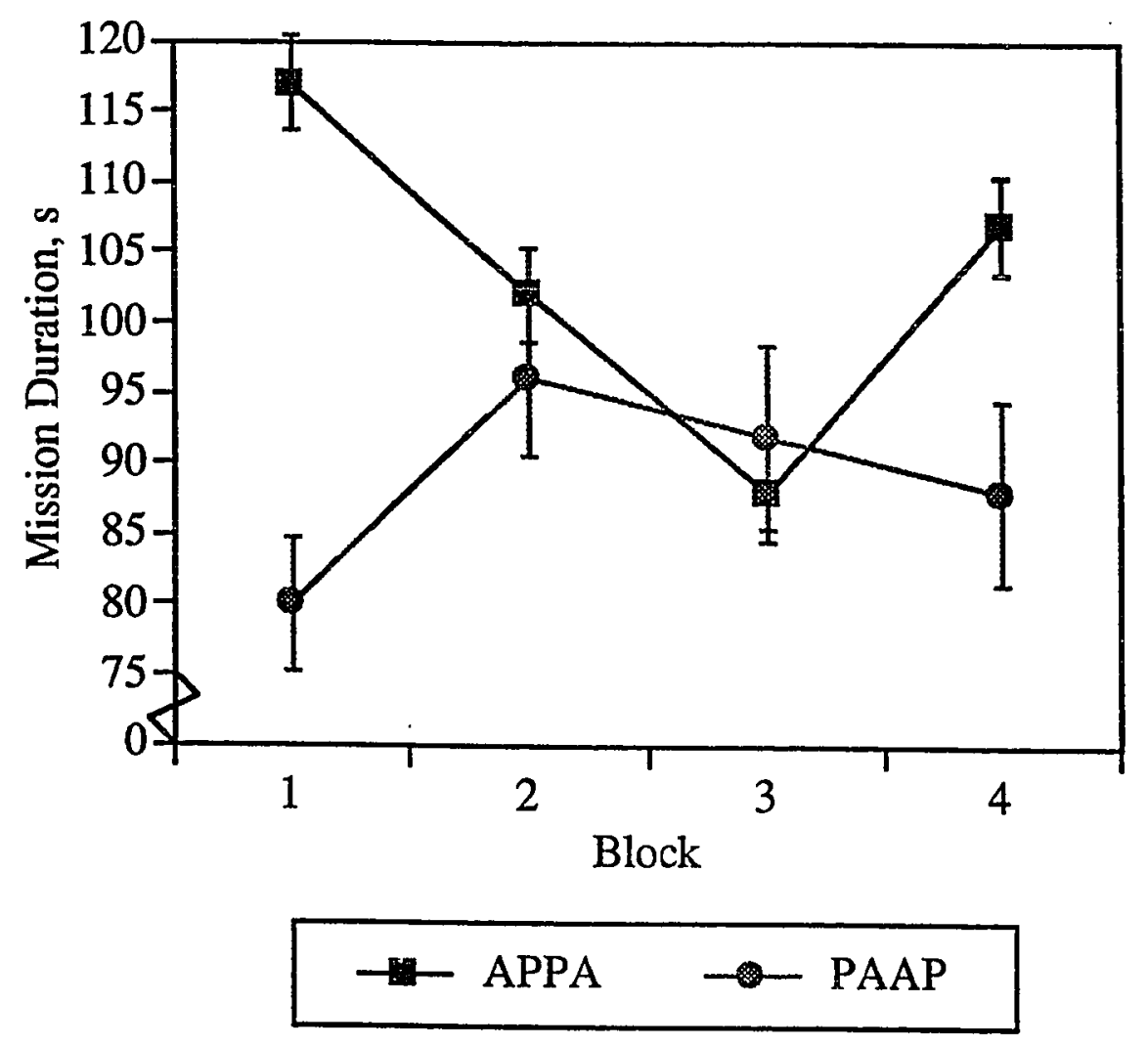

Figure 7: Mission duration 3-way interaction. 
lower than both acceleration means for the APPA group. The last pulse mission duration means for both subject groups were equal (i.e., block 3 in the APPA group and block 4 in the PAAP group).

An analysis of the transitions between consecutive blocks yielded interesting results. Both PA transitions were of the same positive slope. While this is illustrative of the main effect, (that is, pulse mission duration lower than acceleration mission duration), only one of the AP transitions was significantly downward. The single PP transition was downward, again indicating a learning benefit from a previous experience with pulse. Conversely, the single AA transition was unchanged.

Both velocity increment and $\mathrm{X}$ velocity increment data exhibited statistically significant block $x$ range interactions as appear in Figures 8-9. In both cases, the incremental fuel difference between $100 \mathrm{~m}$ and $150 \mathrm{~m}$ was greater for the first half of 18 trials than the second half. This is another manifestation of a practice effect.

An ANOVA was performed on the data collapsed across block and trial to determine which combinations of independent variables were more likely to cause an unsuccessful mission. No statistically significant effects were uncovered. Neither mode was found to be inherently safer than the other. No combination of range and mode was more conducive to errors than any other.

An identical analysis was performed on data derived from the $\mathrm{Y}$ velocity increment data. Y velocity increment data were reduced to indicate merely the incidence of an out-ofplane (y) thrust rather than its magnitude. Again, no statistically significant effects were found.

\section{Discussion}

The finding that fuel consumption levels, measured as velocity increment, were lower in acceleration mode than in pulse mode corroborates the results from the preliminary 
Block x Range Interaction

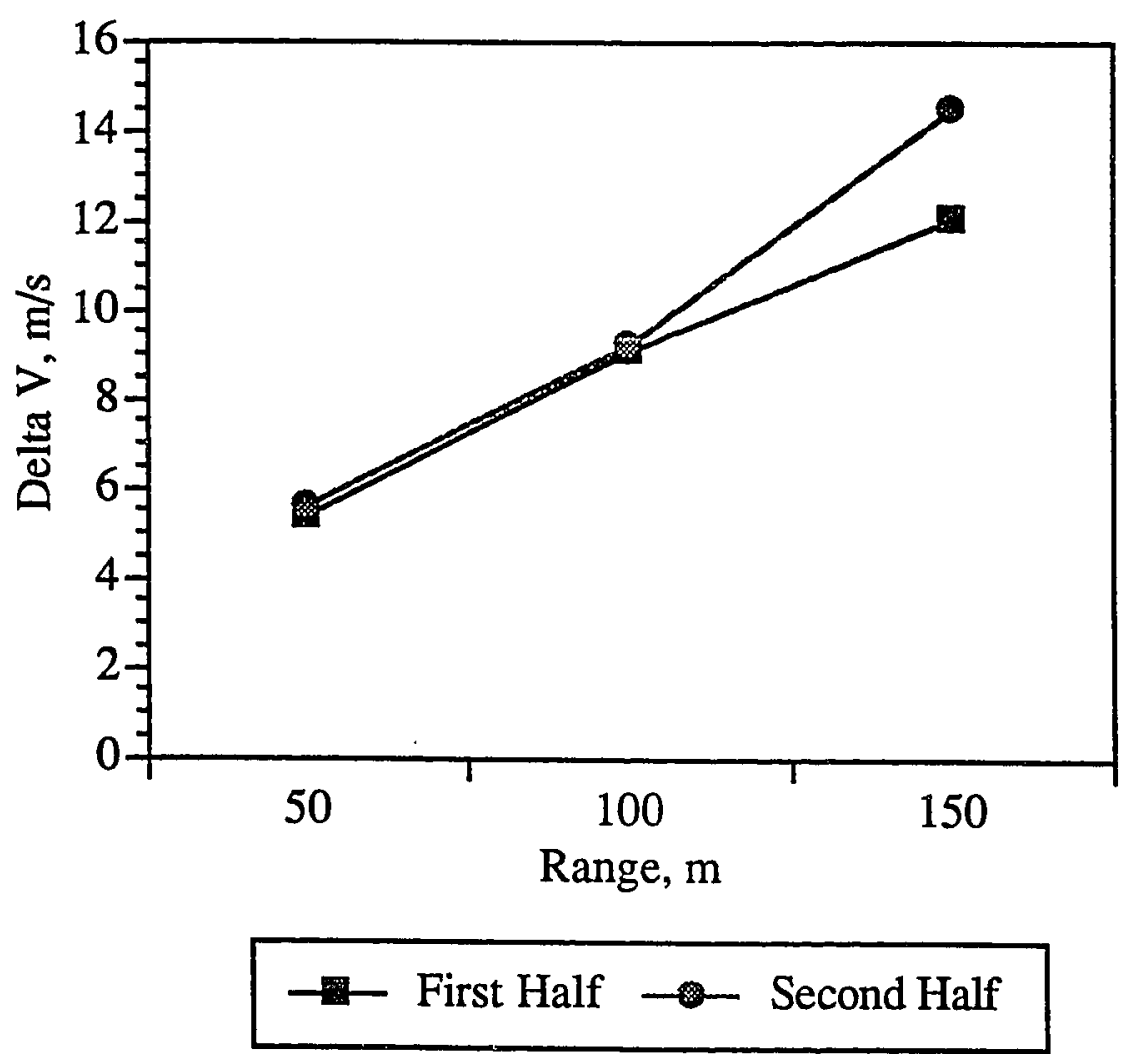

Figure 8: Velocity increment versus range. 
Spacecraft Docking Control Mode Comparison

X Delta V Block x Range Interaction

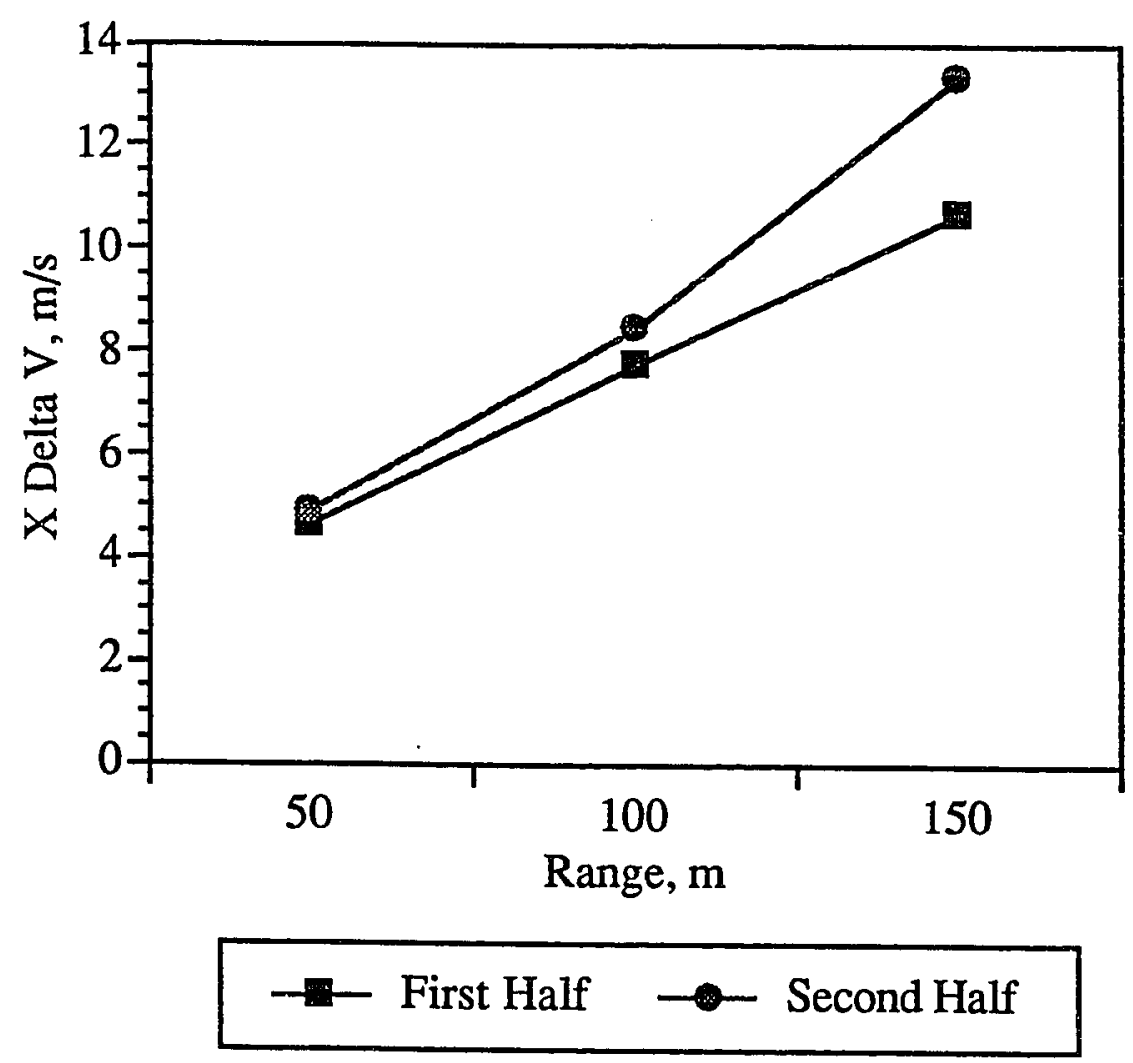

Figure 9: $\mathrm{X}$ velocity increment 2-way interaction. 
experimentation. Pulse mode is not inherently more fuel conservative than acceleration mode as one might infer from studying the appropriate NASA manuals (Oberg, 1988; Sedej \& Clarke, 1985). This is probably due to the greater dynamic range available with acceleration control, allowing for greater flexibility and fine tuning capability.

An alternative design, which would also provide this flexibility, is a variable thrust engine. This is analogous to automobile, aircraft, and boat engines where the fuel flow rate can be varied in real time. This type of engine was used on the ascent stage of the Lunar Module (LM) which worked against the resistive force of the moon's gravity. Without a resistive force, however, this control mode causes velocities to build up too rapidly.

The related discovery that mission duration was lower in pulse mode than acceleration mode could be important for contingency operations such as crew or vehicle rescue. In a case where time is of the essence and the cost of fuel is relatively minor, one might choose to pilot a mission in a pulse mode. The use of fuel derived from lunar oxygen or waste water (Larson \& Evans, 1986) would reduce the cost of fuel. This would alter the docking cost equation making rapid dockings more cost effective. Also, appropriate training before experimentation could lead to more effective use of time and/or fuel. For example, explanations of the peculiarities of orbital mechanics would help a pilot develop heuristics enabling him to improve "mileage."

The direct relationship between range and $\mathrm{X}$ velocity increment is not intuitive. Unlike conventional environments such as air, sea, and land, the force of drag involved in a docking maneuver in orbit is negligible. Energy need not be expended to maintain velocity on orbit. Rather, more fuel was consumed because the greater ranges, and corresponding longer mission durations, enabled higher approach velocities. This increased fuel consumption prevented the mission duration from increasing linearly with range as would happen if average approach velocity were the same, regardless of initial range. 
Practice effects manifested themselves in a number of ways. Mission duration decreased with more trials while $\mathrm{X}$ velocity increment increased with more trials. The mission duration/velocity increment results are related as described earlier. To reduce duration, one must pay for increased velocity with increased fuel consumption.

$\mathrm{X}$ velocity increment was also the only dependent variable to display a block main effect. The "practice effect" is therefore expressed more robustly with $\mathrm{X}$ velocity increment than with mission duration or $\mathrm{X}$ rate since $\mathrm{X}$ velocity increment increased both over trials and over blocks.

The fact that seven statistically significant effects were associated with the $Y$ velocity increment magnitude data but none were discovered for the $\mathrm{Y}$ velocity increment incident data is somewhat surprising. It indicates, for example, that first mode and range influenced the total magnitude of the $y$ thrusts rather than the likelihood of occurrence of an out-of-plane command. Y velocity increment commands were not required for the successful completion of the simulated docking maneuver.

The asymmetrical transfer discovered here is important for researchers investigating the impact of control modes on spacecraft docking operations. This result should be regarded as a forewarning that investigators should be careful when designing experiments and formulating conclusions. The asymmetry illustrates an inconsistent main effect for which one must account before attributing a result to a control mode. In comparing different control modes, experimenters should be sure to provide sufficient intervening practice to prevent the effects of asymmetrical transfer from contaminating the experimental results.

The data from this study demonstrated that dockings could be performed faster, albeit at the expense of greater amounts of fuel, in pulse mode than in acceleration mode. Pulse mode is not definitively more fuel efficient than acceleration mode. This result is 


\section{Spacecraft Docking Control Mode Comparison}

important for long term mission planning and logistics. Further human factors and manual control experimentation are necessary to quantify more fully the manual control operational flight envelope. 
Spacecraft Docking Control Mode Comparison

\section{References}

Adams, J. A. (1989). Human factors engineering. New York: Macmillan Publishing Company.

Aldrin, B. (1990, October/November). The Mars transit system. Air \& Space Smithsonian, pp. 40-47.

Aldrin, B. \& McConnell, M. (1989). Men from earth. New York: Bantam Books.

Baker, D. (1982). The history of manned space flight. New York: Crown Publishers Inc.

Birch, S. (1990, May). Human factors in cockpit design, Aerospace Engineering, pp. 4549.

Brody, A. R. (1987). Spacecraft flight simulation: A human factors investigation into the man-machine interface between an astronaut and a spacecraft performing docking maneuvers and other proximity operations. Unpublished master's thesis, Massachusetts Institute of Technology, Cambridge, MA (see also NASA Contractor Report No. 177502).

Brody, A. R. (1988). Modifications to the NASA Ames space station proximity operations (PROX OPS) simulator (Contractor Report No. 177510). Washington, DC: National Aeronautics and Space Administration.

Brody, A. R. (1989a). The effect of initial velocity on manually controlled remote docking of an orbital maneuvering vehicle to a space station (Paper No. 89-0400). Washington, DC: American Institute of Aeronautics and Astronautics.

Brody, A. R. (1989b). Remote operation of an orbital maneuvering vehicle in simulated docking maneuvers (Conference Publication No. 3059). In S. Griffin (Ed.), Proceedings of the Third Annual Workshop on Space Operations Automation and Robotics (SOAR '89) (pp. 471-475). Washington, DC: National Aeronautics and Space Administration. 
Brody, A. R. (1990a). Evaluation of the " $0.1 \%$ rule" for docking maneuvers. ournal of Spacecraft and Rockets. 27, 7-8.

Brody, A. R. (1990b). EivaN: An interactive orbital trajectory planning tool. Journal of Spacecraft and Rockets, 6, 681-683.

Brody, A. R. \& Ellis. S. R. (1990a). Factors influencing manual ability to recover from an anomalous thruster input during a simulated docking maneuver, (Paper No. 900519). Washington DC: American Institute of Aeronautics and Astronautics.

Brody, A. R. \& Ellis, S. R. (1990b). Manual control aspects of space station docking maneuvers (Technical Paper No. 901202). Warrendale, PA: Society of Automotive Engineers.

Brody, A. R. \& Ellis. S. R. (1990c). Effect of an anomalous thruster input during a simulated docking maneuver. Journal of Spacecraft and Rockets, 6, 630-633.

Brody, A. R. \& Ellis. S. R. (1991). Recovery from an anomalous thruster input during a simulated docking maneuver (Conference Publication No. 3103). In R. T. Savely (Ed.), Proceedings of the Fourth Annual Workshop on Space Operations Automation and Robotics (SOAR '90) (pp. 557-560). Washington, DC: National Aeronautics and Space Administration.

Clark, H. J. (1965). Space rendezvous using visual cues only, (Technical Report No. 6510). Wright-Patterson Air Force Base, Ohio: Aerospace Medical Research Laboratories.

Clark, P. (1988). The Soviet manned space program. New York: Orion Books.

Collins, M. (1974). Carrying the Fire An astronaut's journeys. New York: Bantám Books.

Edwards, E. (1988). Introductory overview. In E. L. Wiener \& D. C. Nagel (Eds.), Human Factors in Aviation (pp. 3-25). San Diego: Academic Press, Inc. 
Ellis, S. R. and Grunwald, A. J. (1990). The dynamics of orbital maneuvering: Design and evaluation of a visual display aid for human controllers, In Space vehicle flight mechanics, (Conference Proceedings No. 489, pp. 29-1 - 29-13). Neuilly Sur Seine, France: Advisory Group for Aerospace Research \& Development.

Evans, W. B. \& Czarnik, M. R. (1967). Summary of Rendezvous Operations, In Gemini Summary Conference (NASA Special Publication No. 138, pp. 7-19). Washington, DC: National Aeronautics and Space Administration. (NTIS No. N68-14941)

Foushee, H. C. \& Helmreich, R. L. (1988). Group interaction and flight crew performance. In E. L. Wiener \& D. C. Nagel (Eds.), Human Factors in Aviation (pp. 189-227). San Diego: Academic Press, Inc.

Friedman L., H., \& Heinsheimer, T. (1990, July 2-8). Build a U.S.-Soviet team for mars. Space News, pp. 15-16.

Grether, W. F. (1963). Human performance capabilities for military operations in space. In Lectures in aerospace medicine (pp. 77-102). Brooks Air Force Base, TX: USAF School of Aerospace Medicine, Aerospace Medical Division.

Grunwald, A. J. \& Ellis. S. R. (1988). Interactive orbital proximity operations planning system (Technical Paper No. 2839). Washington, DC: National Aeronautics and Space Administration.

Haines, R. F. (1986). Design and development of a space station proximity operations research and development mockup (Technical Paper No. 861785). Warrendale, PA: Society of Automotive Engineers.

Haines, R. F. (1987). Space vehicle approach velocity judgments under simulated visual space conditions (Technical Memorandum No. 89437). Washington, DC: National Aeronautics and Space Administration. 
Spacecraft Docking Control Mode Comparison

Hartley, C. S., Cwynar, D. J., Garcia, K. D., Schein, R. A. (1986). Capture of satellites having rotational motion. In Proceedings of the Human Factors Society 30th Annual Meeting (pp. 875-879). Santa Monica, CA: The Human Factors Society, Inc.

Hillyer, M. S. (1986, September). Cosmonauts have the right stuff, too: A conversation with Vladimir Dzhanibekov. Space World, pp. 17-20.

Hoagland, M. (1984). Winging it in the 1980s: Why guidelines are needed for cockpit automation. In Third Aerospace Technology Conference Proceedings (pp. 155162). Warrendale, PA: Society of Automotive Engineers.

Kantowitz, B. H. \& Casper, P. A. (1988). Human workload in aviation. In E. L. Wiener \& D. C. Nagel (Eds.), Human Factors in Aviation (pp. 157-187). San Diego: Academic Press, Inc.

Kiernan, V. (1990, December 3-9). New Progress capsule completes successful samplereturn mission. Space News, p. 28.

Kramer, S. B. (1990, February/March). The rescue of Salyut 7. Air \& Space Smithsonian, pp. 54-59.

Larson, V. R. \& Evans, S. A. (1986). Propulsion for the space station (International Astronautical Federation No. 86-182). New York: American Institute of Aeronautics and Astronautics.

Lee, E., \& Wu. A. (1987). Space station proximity operations workstation docking simulation (Technical Note No. 87-7104-519-13). Palo Alto, CA: Sterling Software.

Meshcheryakov, I. P., \& Minaev. S. A. (1976). Construction and investigation of an information model of the process of approach of piloted spacecraft. Kosmicheskie Issledovaniya. 15, 804-807. 
Spacecraft Docking Control Mode Comparison

Meshcheryakov, I. P., Sal'nitskii, V. P. \& Nechaev, A. P. (1978). Engineeringpsychological study of information imaging systems. Kosmicheskie Issledovaniya. $16,453-455$.

Mueller, G. E. (1967, February 1-2). Introduction. In Gemini Summary Conference. (NASA Special Publication No. 138, pp. 1-3). Washington, DC: National Aeronautics and Space Administration. (NTIS No. N68-14941)

Nagel. D. C. (1988). Human error in aviation operations. In E. L. Wiener \& D. C. Nagel (Eds.), Human Factors in Aviation (pp. 263-303). San Diego: Academic Press, Inc.

NASA Lyndon B. Johnson Space Center (1985, February). Proceedings of the Rendezvous and Proximity Operations Workshop. Houston, TX: National Aeronautics and Space Administration.

Newkirk, D. (1990). Almanac of soviet manned space flight. Houston, TX: Gulf Publishing Company.

Novikov, U. (1968). Docking in space a complex problem. (Joint Publications Research Service No. 45653). Washington, DC: Department of Commerce.

Oberg, J. E. (1988). Rendezvous and proximity operations handbook. (JSC-10589). Houston TX: NASA Lyndon B. Johnson Space Center Mission Operations Directorate Flight Design \& Dynamics Division.

Poulton, E. C. (1974). Tracking skill and manual control. New York: Academic Press, Inc.

Rains, L. (1990a, June 10-16). Kristall, Mir dock on second try; space walk next. Space News, pp. 1, 4, 21.

Rains, L. (1990b, September 10-16). Soviets seek to solve Mir bottleneck with Progress M. Space News, p. 8. 
Sedej, D. T. \& Clarke, S. F. (1985). Rendezvous/Proximity operations workbook (RNDZ 2102). Houston TX: NASA Lyndon B. Johnson Space Center Mission Operations Directorate Training Division Flight Training Branch.

Soviet Salyut 7. (1991, February 11). Aviation Week \& Space Technology, p. 15.

Terelak, J. F. (1989). Trends in Poland in space psychology research. Aviation Space and Environmental Medicine. 60, 352-360.

Wickman, L. (1990, April/May). The effects of automation on work in space. Paper presented at the Society of Logistics Engineers/American Institute of Aeronautics and Astronautics Third Space Logistics Symposium 'Space Logistics in Transition,' Colorado Springs, CO.

Wiener. E. L. (1988). Cockpit Automation. In E. L. Wiener \& D. C. Nagel (Eds.), Human Factors in Aviation (pp. 433-461). San Diego: Academic Press, Inc. 


\section{APPENDIX}

APPROVED BY THE DESIGN AND ANALYSIS COMMITTEE
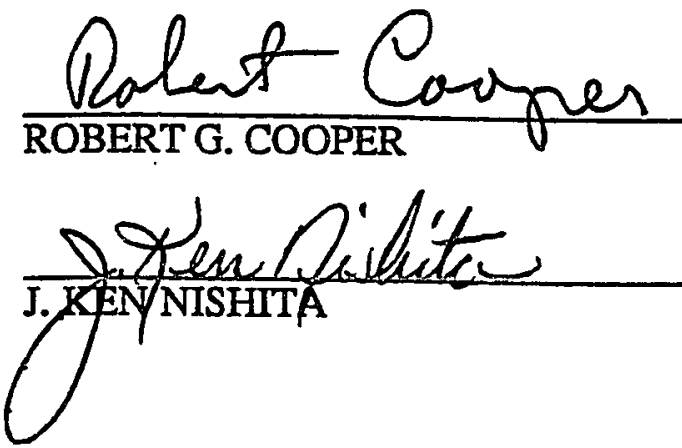